\title{
A Chemical Strategy for Intracellular Arming of an Endogenous Broad-Spectrum Antiviral Nucleotide
}

Kellan T. Passow ${ }^{\dagger}$; Haley S. Caldwell ${ }^{\wedge}$; Kiet A. Ngo^; Jamie J. Arnold $\$ \perp$; Nicole M. Antczak ${ }^{\# \Perp}$; Anoop Narayanan§; Joyce Jose ${ }^{\S}$; Shana J. Sturla\#; Craig E. Cameron ${ }^{\S}$; Alexander T. Ciota ${ }^{\star}$; Daniel A. Harki ${ }^{\dagger *}$

${ }^{\dagger}$ Department of Medicinal Chemistry, University of Minnesota, Minneapolis, MN 55455 USA

${ }^{\ddagger}$ Department of Biomedical Sciences, State University of New York at Albany School of Public Health, Albany, NY 12144 USA

'The Arbovirus Laboratory, Wadsworth Center, New York State Department of Health, Slingerlands, NY 12201 USA

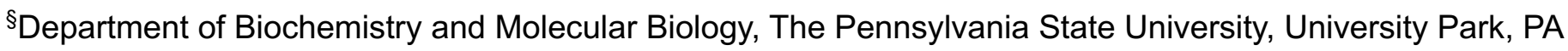
16802 USA

\#Department of Health Sciences and Technology, ETH Zürich, Zürich 8092, Switzerland

"Huck Institutes of the Life Sciences, The Pennsylvania State University, University Park, PA 16802 USA

*Corresponding author: daharki@umn.edu

\section{Present Addresses}

¿Department of Microbiology and Immunology, University of North Carolina School of Medicine, Chapel Hill, NC 27599 USA

«Department of Chemistry, Skidmore College, Saratoga Springs, NY 12866 USA 


\section{Table of Contents}

I. Supporting Information Figures

S3-S7

II. ${ }^{1} \mathrm{H},{ }^{13} \mathrm{C}$, and ${ }^{31} \mathrm{P}$ NMR Spectra and HPLC Traces of Synthesized Compounds

S8-S34

III. Reference 


\section{Supporting Information Figures}

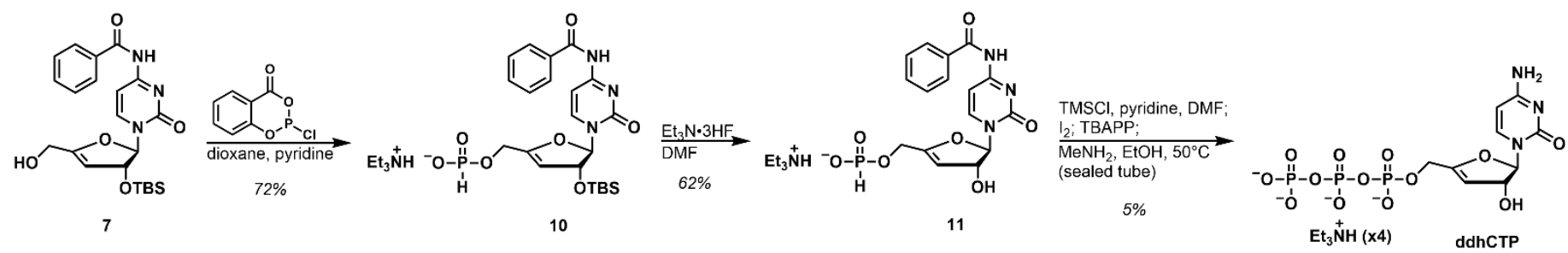

Scheme S1. Synthesis of ddhCTP from 7.
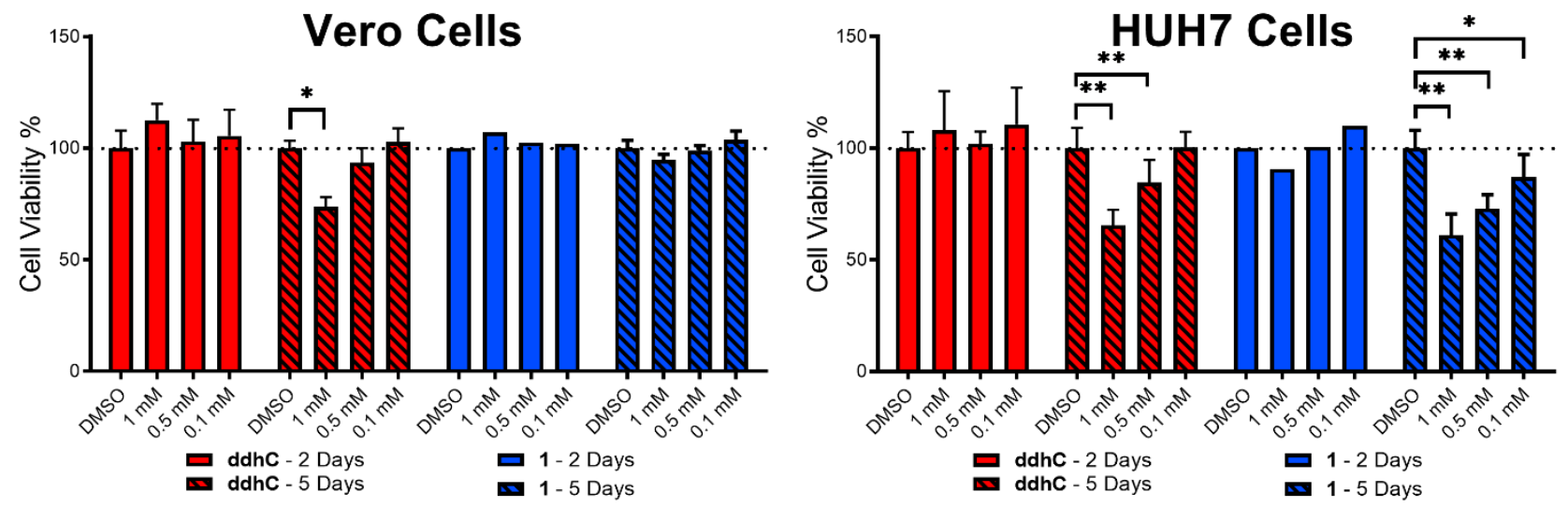

Figure S1. Dose-dependent cytotoxicity of ddhC (red) and 1 (blue) in Vero (top) HUH7 (bottom) cells. Viability measured at 2 days (solid bars) and 5 days (patterned bars). Dotted line at added for clarity to mark $100 \%$ viability. Reported values are the mean of at least 3 biological replicates (3 technical replicates per) \pm standard deviation. Statistical significance relative to control DMSO samples is indicated by ${ }^{*} p<0.05$ or ${ }^{* *} p<0.01$. 

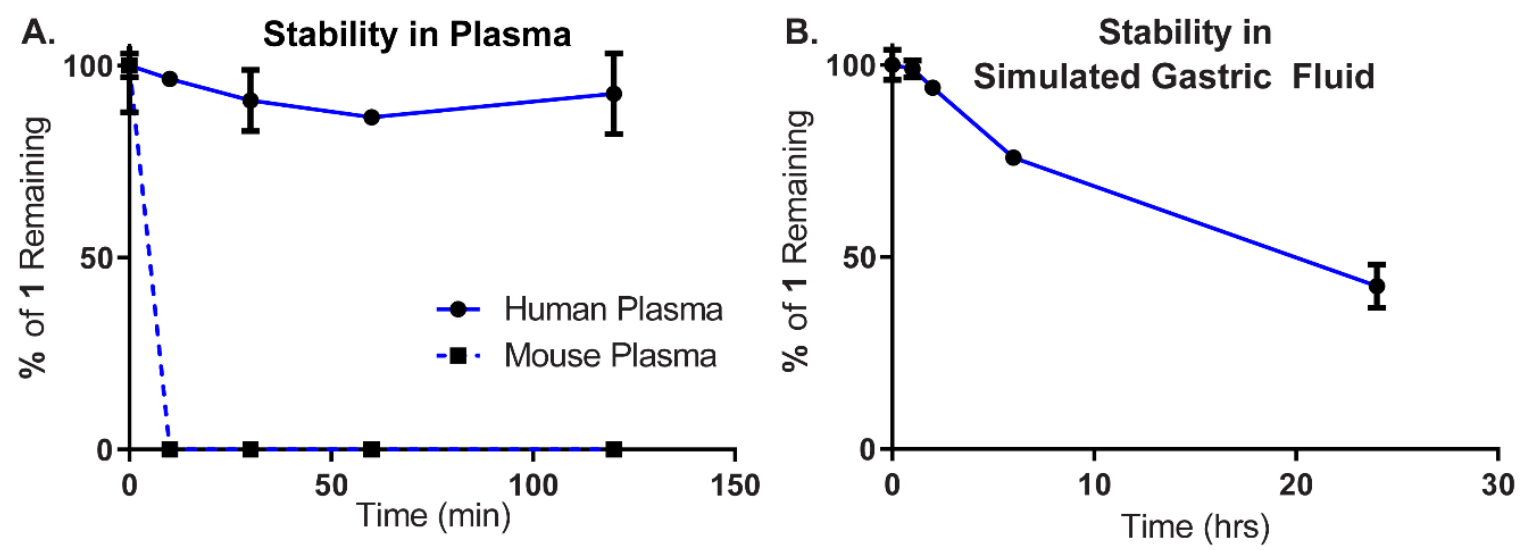

\begin{tabular}{l|cc|c}
$\begin{array}{l}\text { C. } \\
\text { Compound }\end{array}$ & \multicolumn{2}{c}{ Mean Papp (nm/s) } & $\begin{array}{r}\text { Efflux } \\
\text { Ratio }\end{array}$ \\
\cline { 2 - 4 }$\underline{1}$ & 0.3 & 16.4 & 50.7 \\
A to B & B to A & \\
ddhC & 1.1 & 3.2 & 2.83 \\
Sofosbuvir & $0.46^{*}$ & n/a & n/a
\end{tabular}

Figure S2. A. Stability of 1 in human and mouse plasma. B. Stability of 1 in simulated gastric fluid. C. Permeability of $\mathbf{1}$ and $\mathbf{d d h} \mathbf{C}$ through a Caco-2 cell line monolayer. *Published PAMPA data for sofosbuvir (see J. Med. Chem. 2010, 53, 7202). ${ }^{1}$

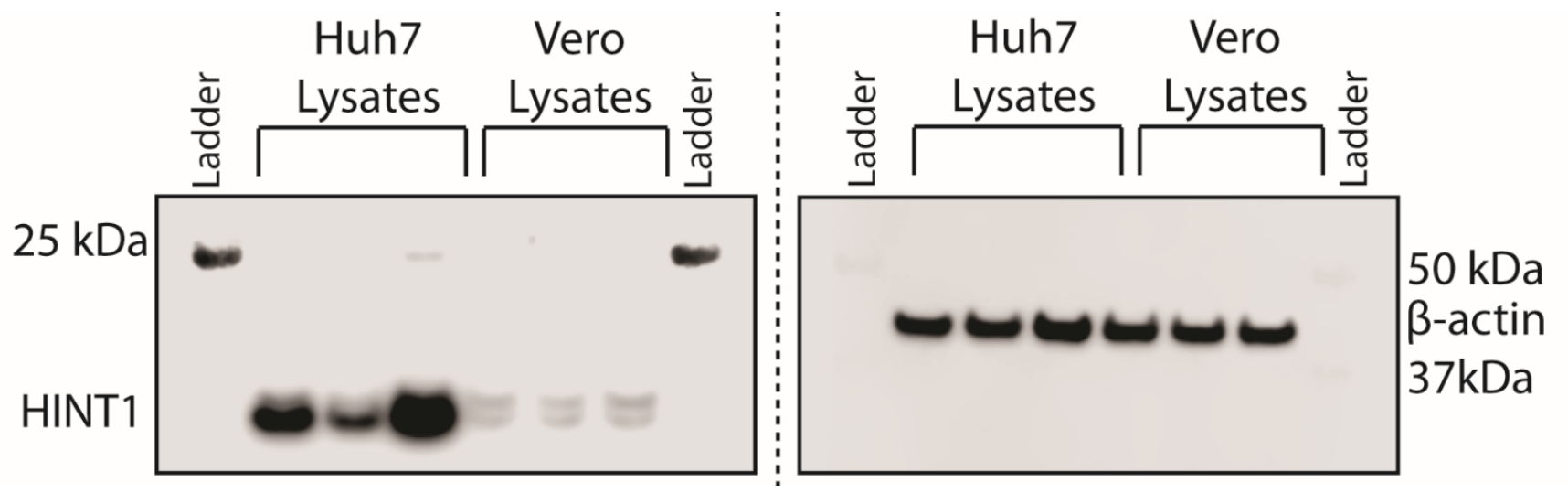

Figure S3. Left: HUH7 and Vero cell lines were blotted for the enzyme HINT1. Right: Blots were washed and re-blotted for $\beta$-actin loading control. Ladder incorporated for molecular weight reference. Three separate passages of each cell line were collected for comparison. 


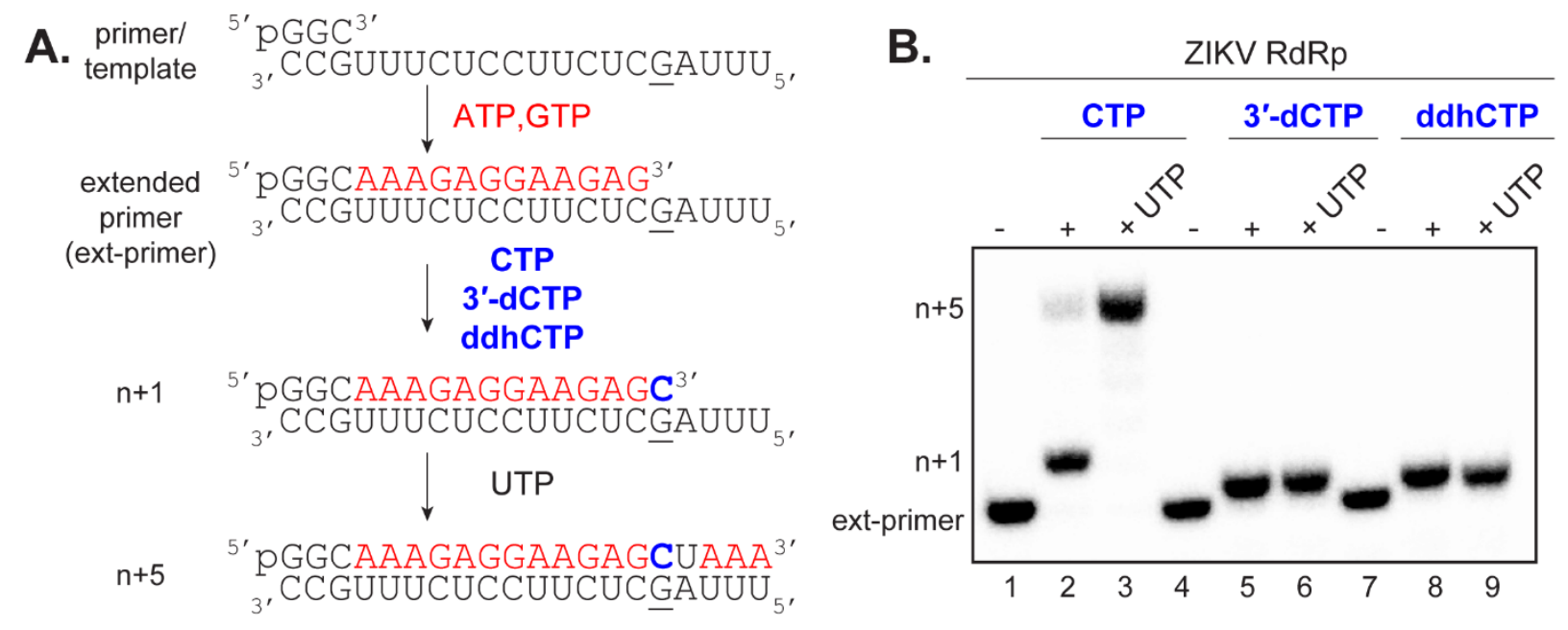

Figure S4. Synthetic ddhCTP is utilized as a substrate by ZIKV NS5 RdRp and chain terminates RNA synthesis. A. Schematic of primer extension assay. B. ZIKV RdRp-catalyzed incorporation of CTP, 3'-dCTP, or ddhCTP. Once incorporated, both 3'-dCTP and ddhCTP inhibit subsequent nucleotide incorporation demonstrating chain termination. 
256.rdb (HLB-0532256): "Linear" Re gression ("1 / $\left(x^{*} x\right)^{-2}$ weighting): $y=0.00168 x+0.017$ ( $\left.r=0.9994\right)$

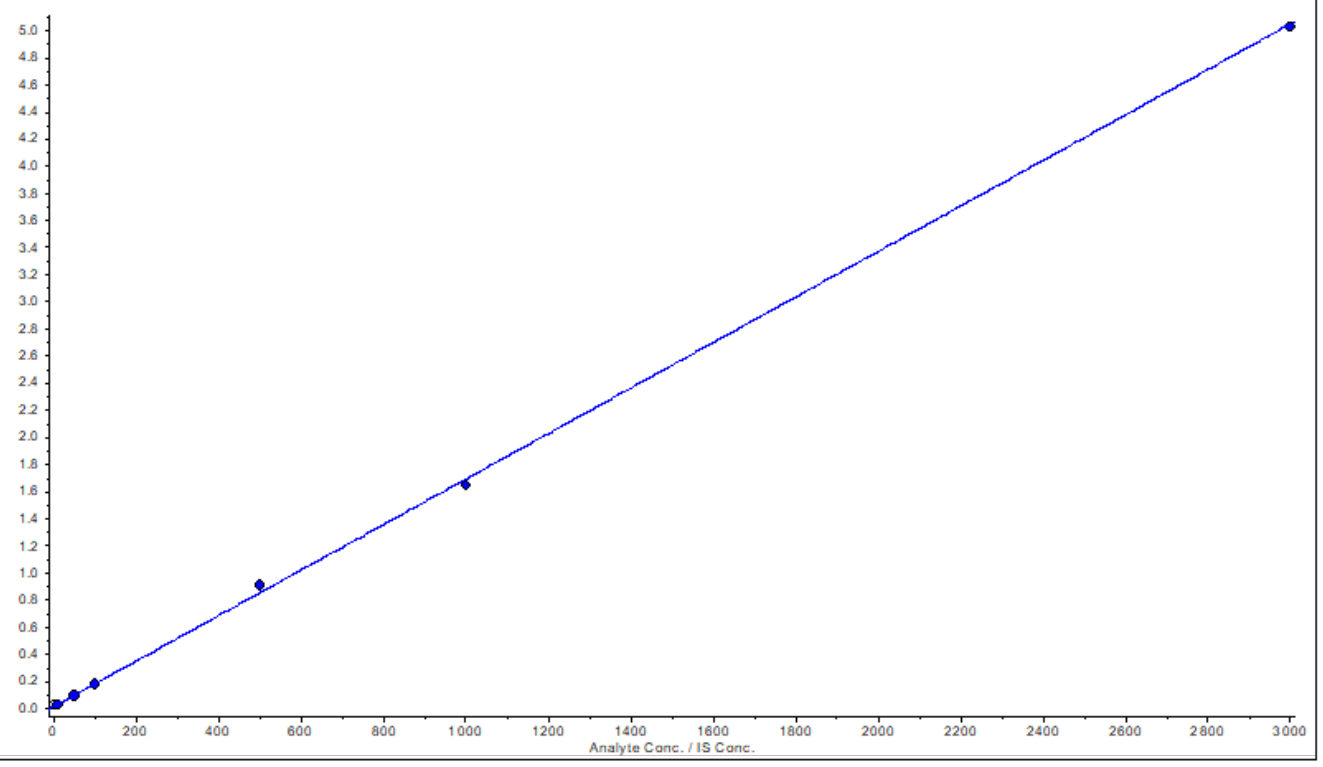

Figure S5. Calibration curve for analyte ddhCTP.

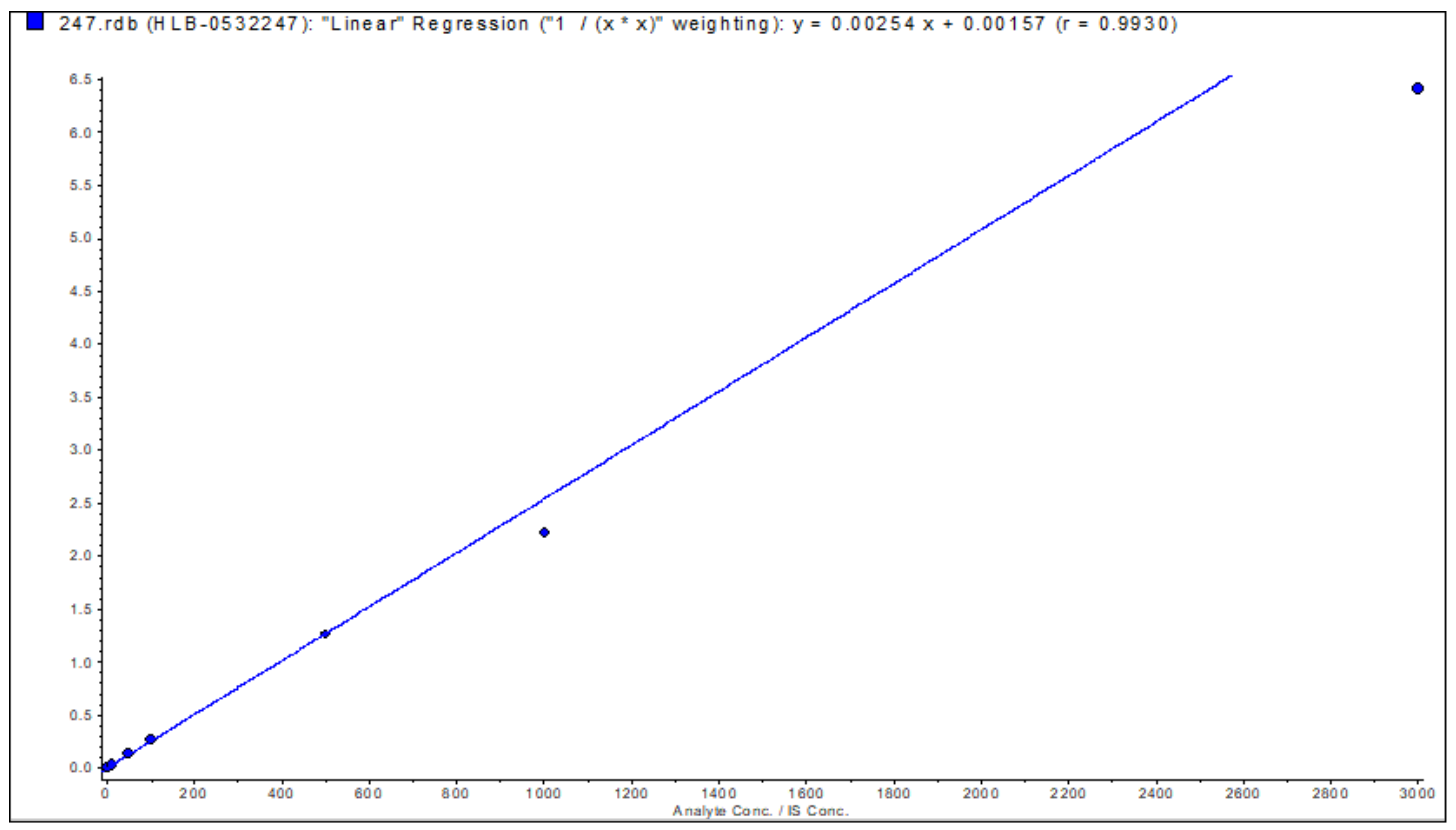

Figure S6. Calibration curve for analyte 1. 
Compound name: HLB0532246

Correlation coefficient: $r=0.996972, r^{\wedge} 2=0.993953$

Calibration curve: 0.00034633 * $x+-9.75809 e-005$

Response type: Internal Std ( Ref 2 ), Area * (IS Conc. / IS Area )

Curve type: Linear, Origin: Exclude, Weighting: $1 / x^{\wedge} 2$, Axis trans: None
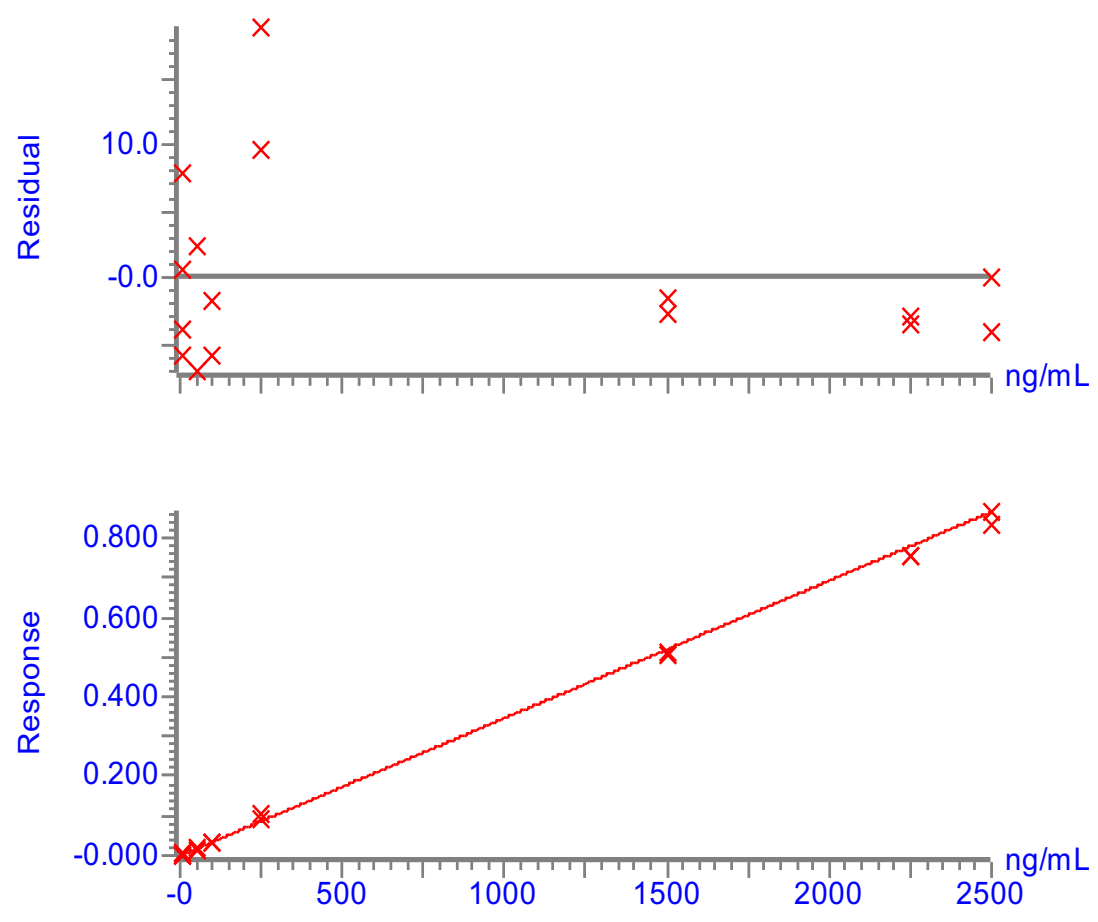

Figure S7. Calibration curve for analyte ddhC. 
XVI. ${ }^{1} \mathrm{H},{ }^{13} \mathrm{C}$, and ${ }^{31} \mathrm{P}$ NMR Spectra and HPLC Traces of Synthesized Compounds

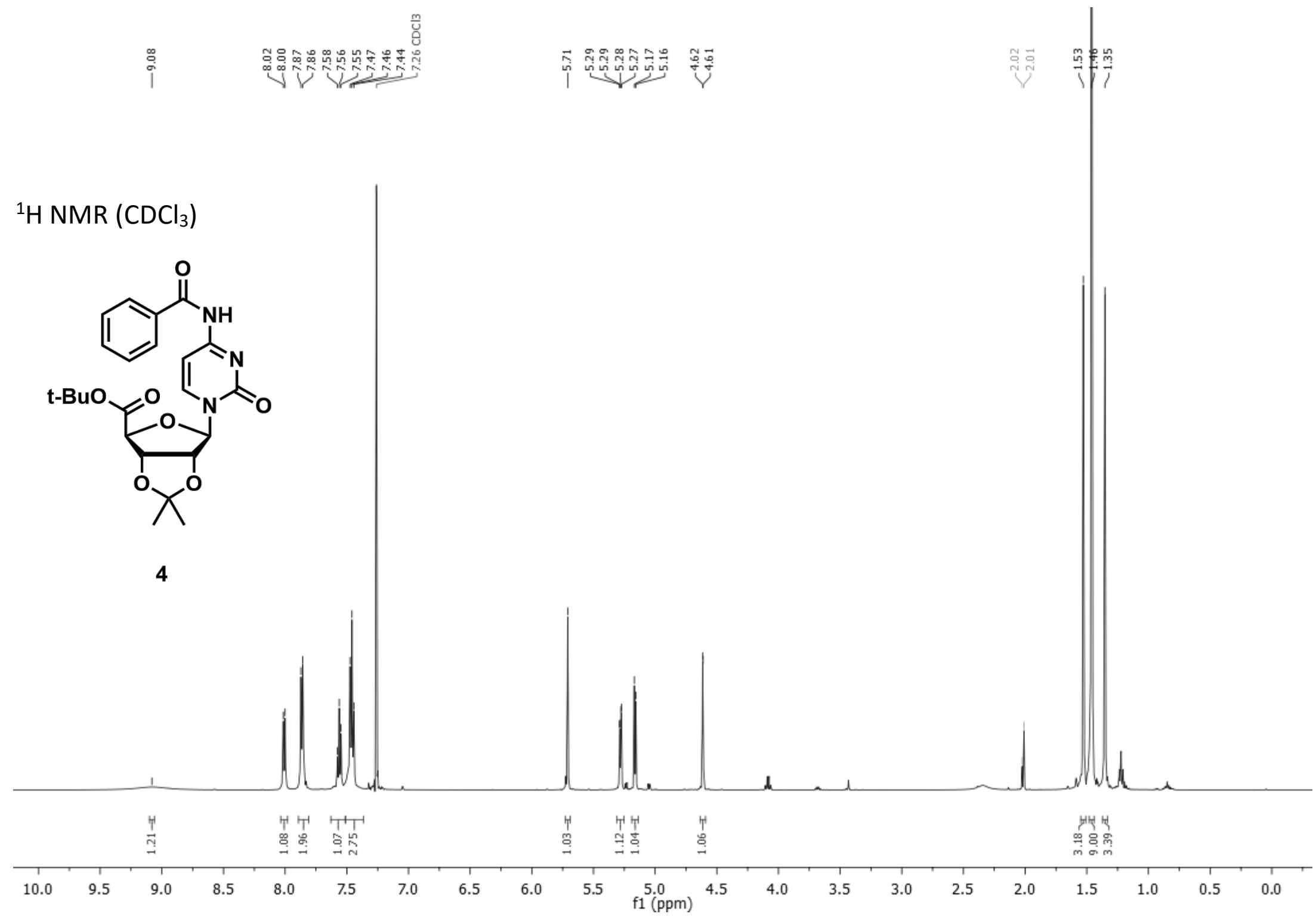




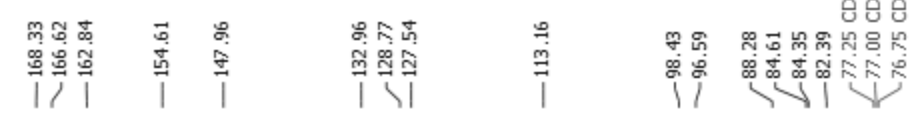

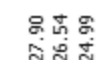

${ }^{13} \mathrm{C} \mathrm{NMR}\left(\mathrm{CDCl}_{3}\right)$
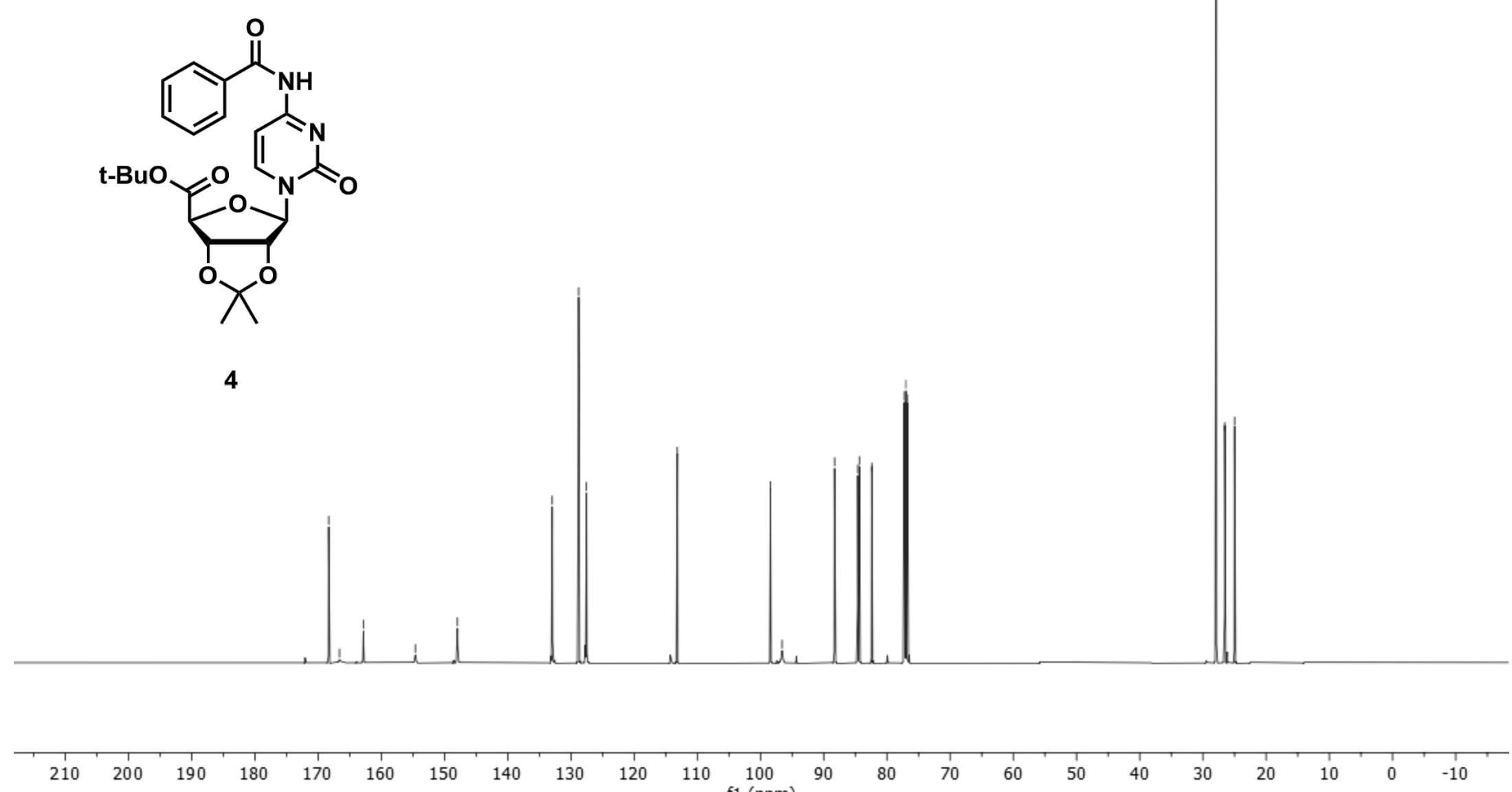


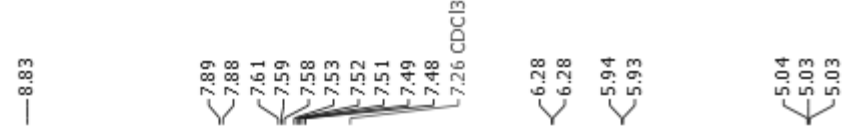

${ }^{1} \mathrm{H}$ NMR $\left(\mathrm{CDCl}_{3}\right)$

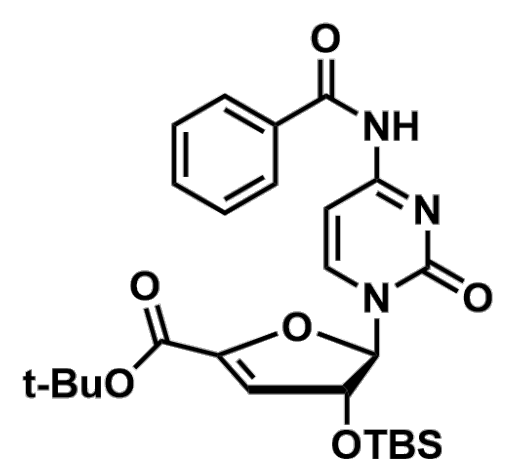

5

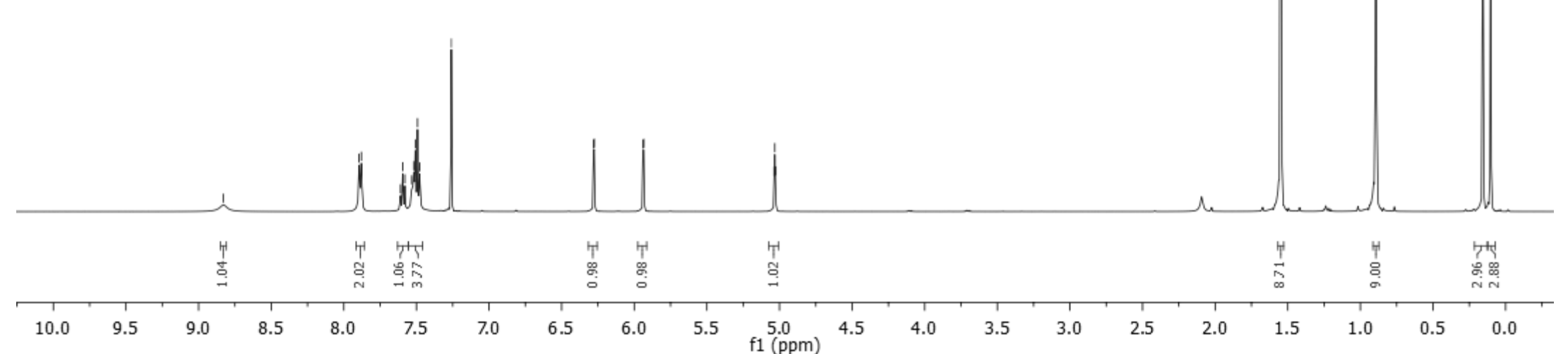




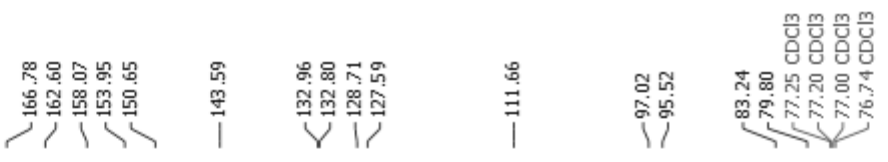

${ }^{13} \mathrm{C} \mathrm{NMR}\left(\mathrm{CDCl}_{3}\right)$<smiles>CCCCOC(=O)C1=C[C@@H](O[Sb](=O)(=O)c2ccccc2)[C@H](n2ccc(NC(=O)c3ccccc3)nc2=O)O1</smiles>

5
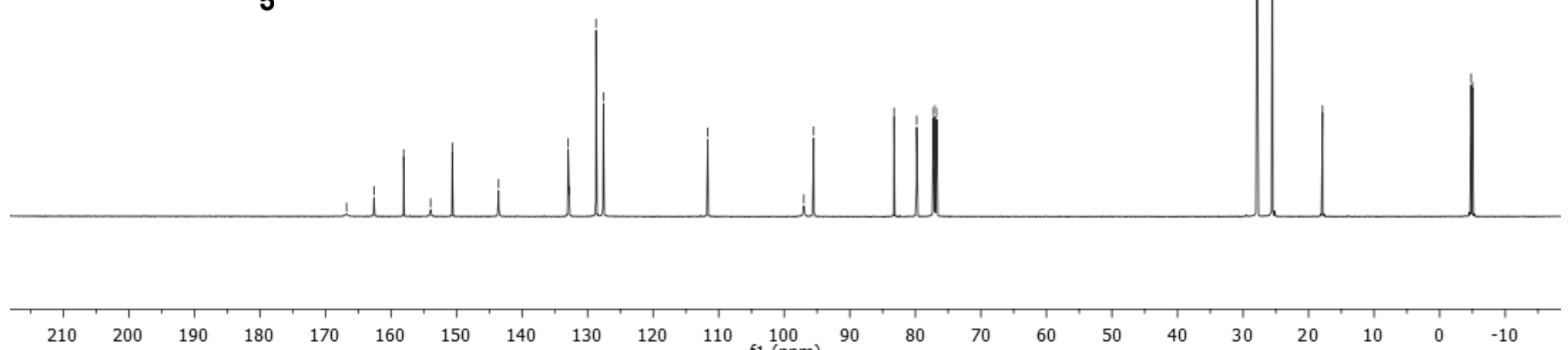

$180 \quad 17$

160

$150 \quad 140$ $\begin{array}{llll}130 & 120 & 110 & 100 \\ & & & f(p p m)\end{array}$

80

$70 \quad 60$

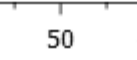

40 


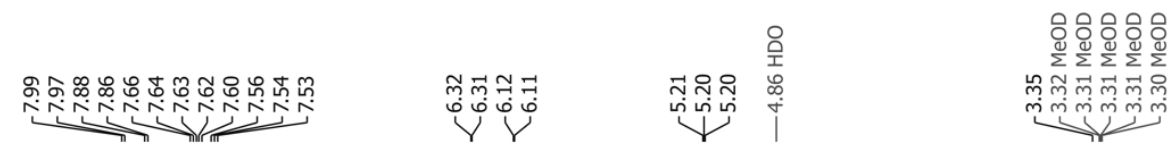

${ }^{1} \mathrm{H}$ NMR (MeOD)

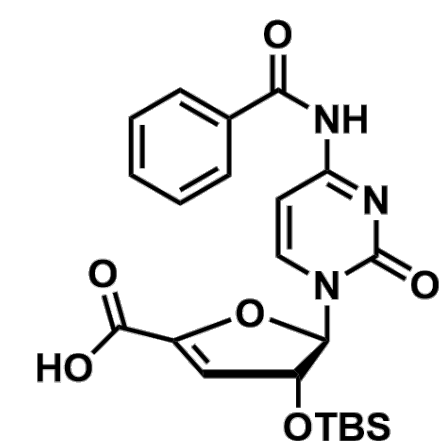

6

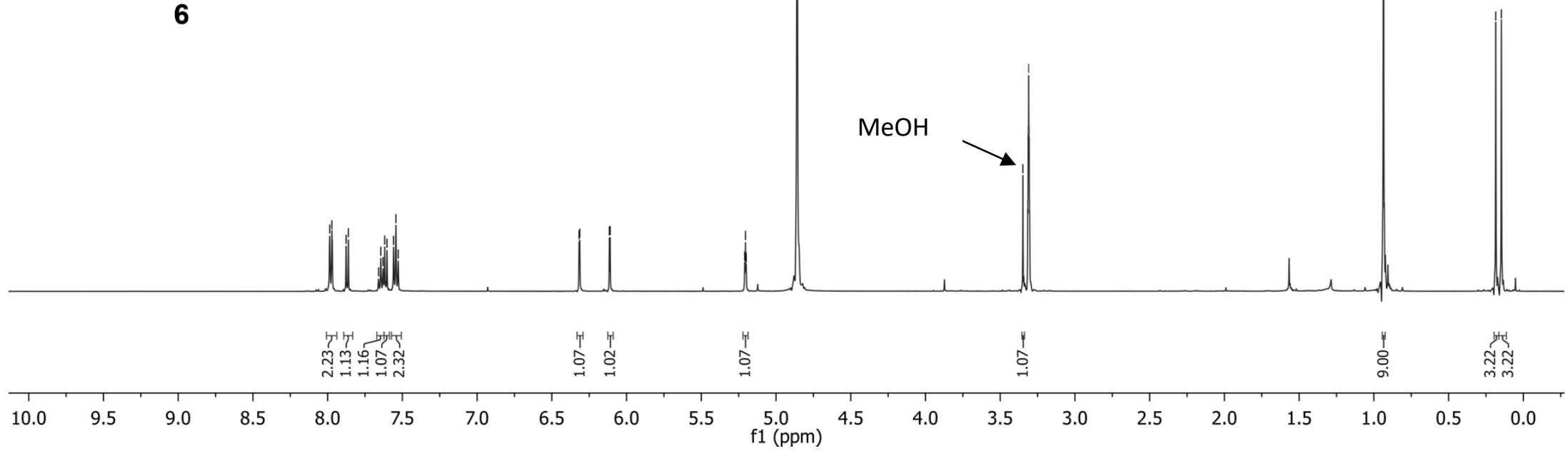




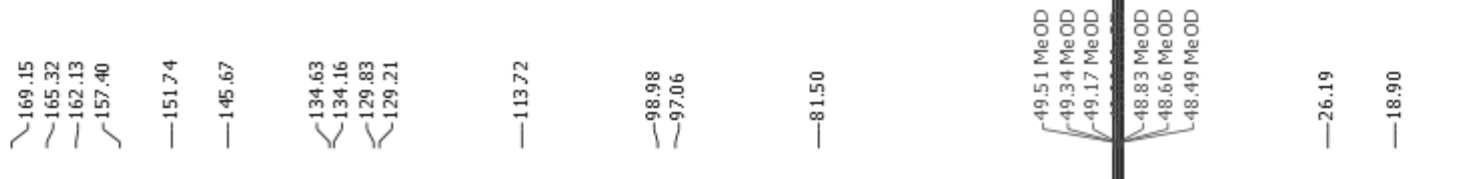

Y

${ }^{13}$ C NMR (MeOD)<smiles>CS(=O)(=O)OC1CC(C(=O)O)OC1n1ccc(NC(=O)c2ccccc2)nc1=O</smiles>

6

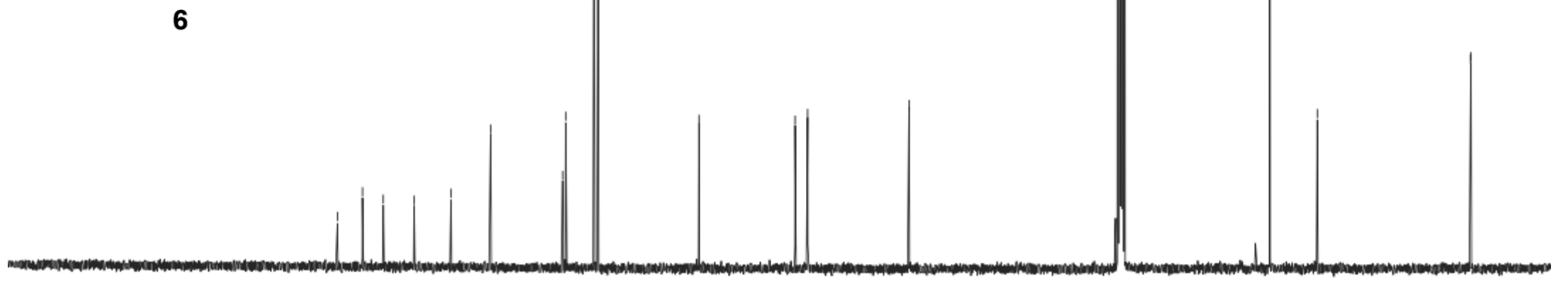




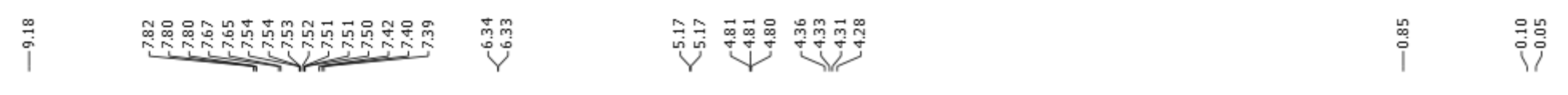

${ }^{1} \mathrm{H} \mathrm{NMR}\left(\mathrm{CDCl}_{3}\right)$

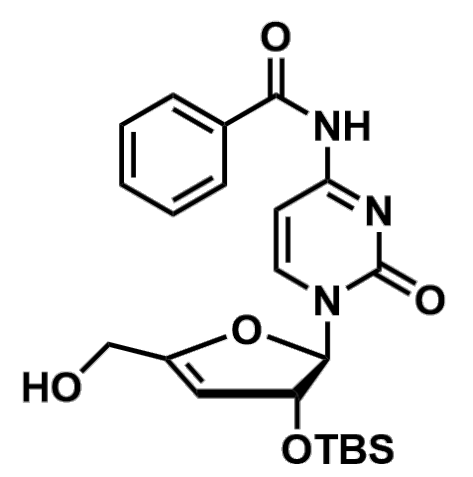

7
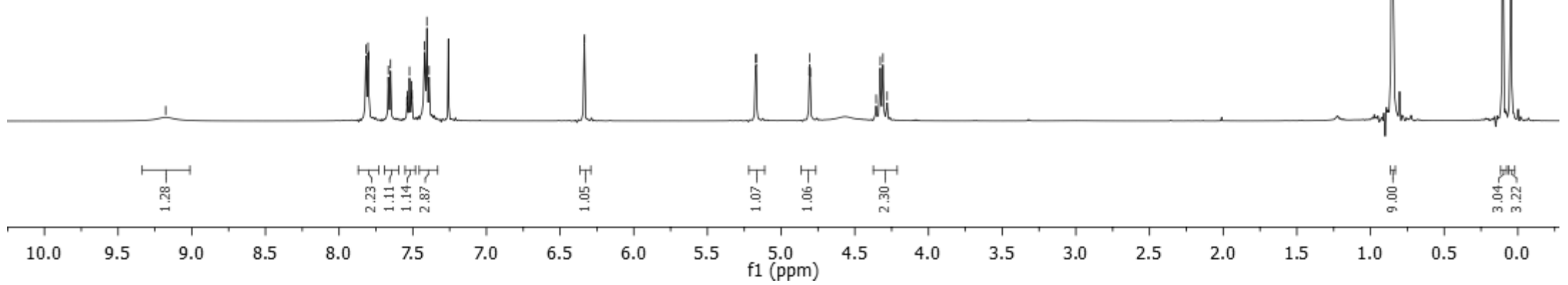
${ }^{13} \mathrm{CNMR}\left(\mathrm{CDCl}_{3}\right)$

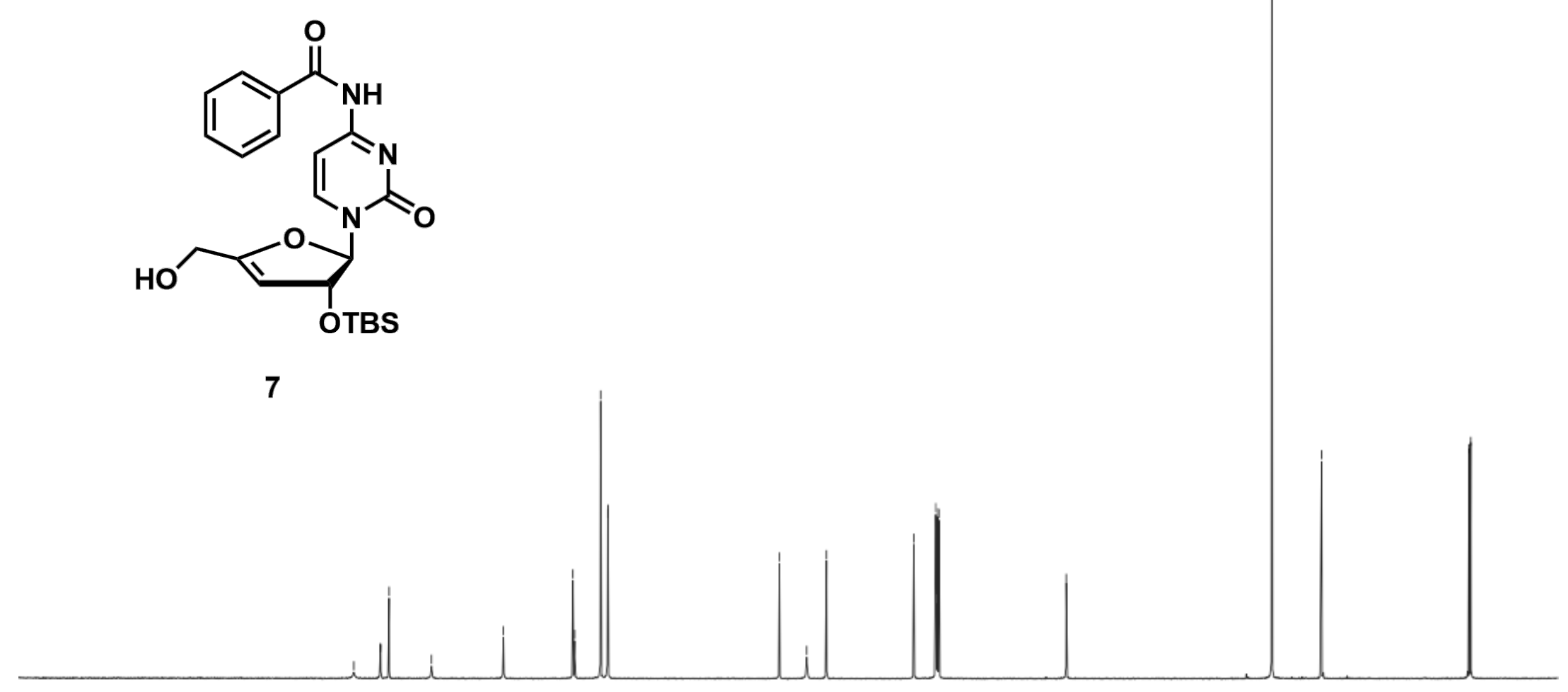

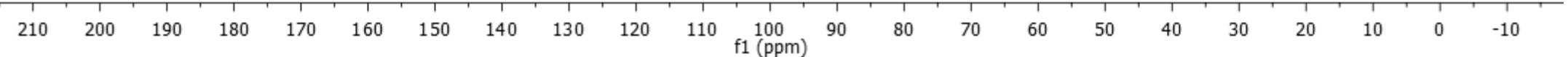


${ }^{1} \mathrm{H} \mathrm{NMR}\left(\mathrm{CDCl}_{3}\right)$

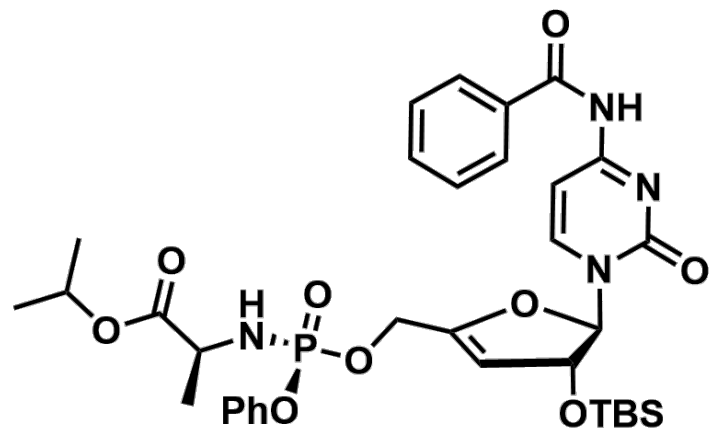

8

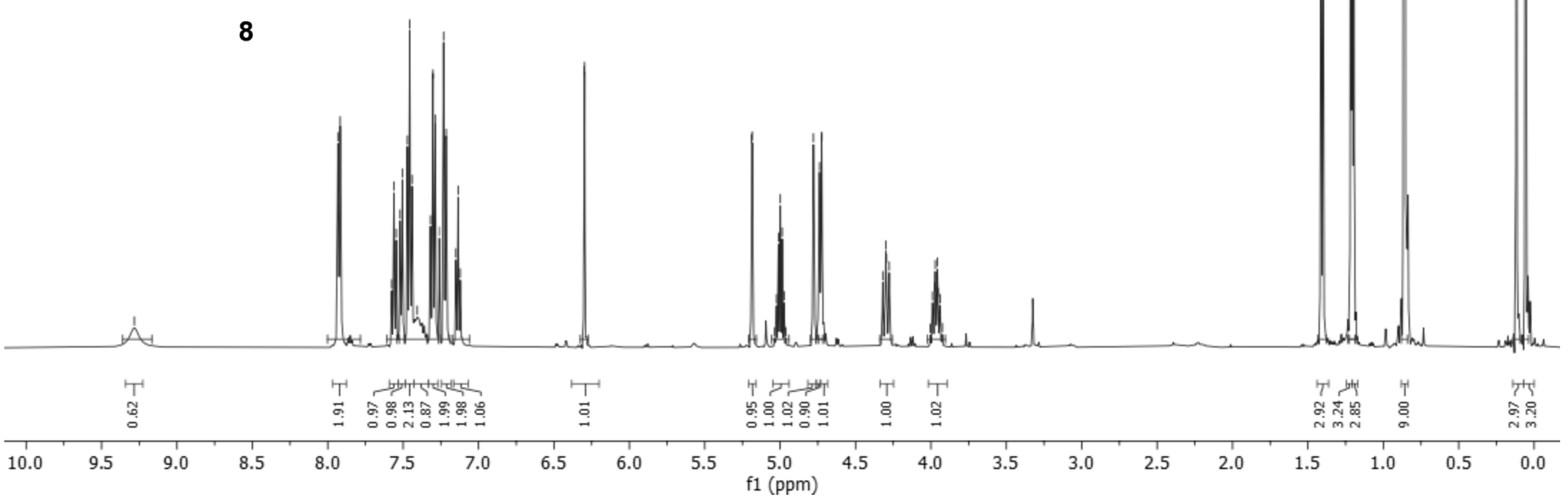




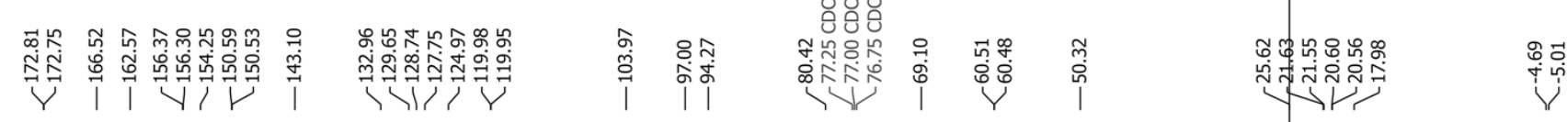

${ }^{13} \mathrm{C} \mathrm{NMR}\left(\mathrm{CDCl}_{3}\right)$

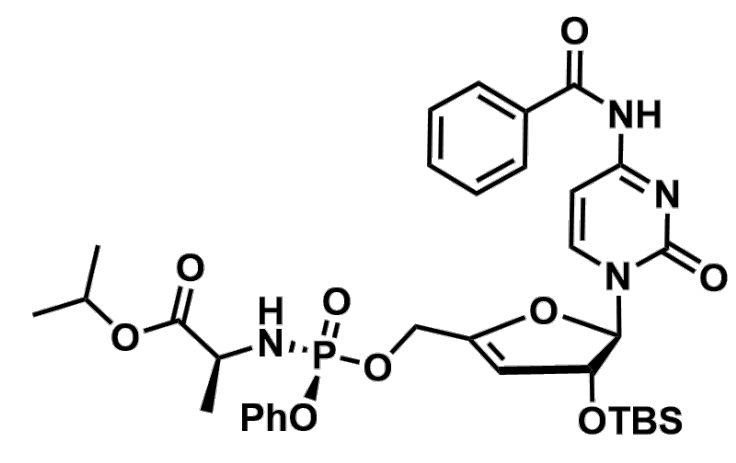

8

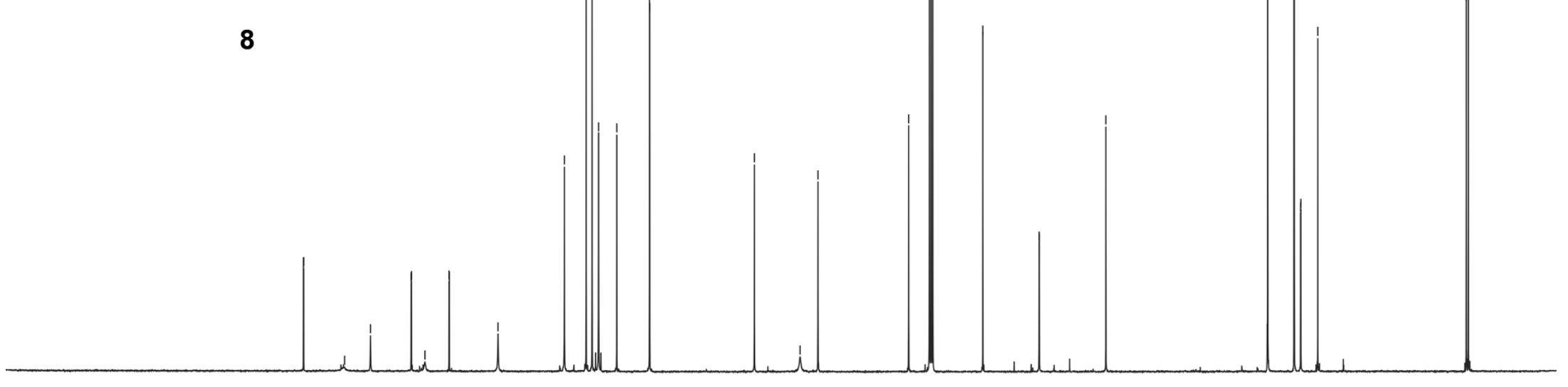

210

$200 \quad 190$

$180 \quad 170$

$160 \quad 150 \quad 140$

130

$110 \underset{f 1(\mathrm{ppm})}{100} 90$

$80 \quad 70$

60

$30 \quad 20$ 


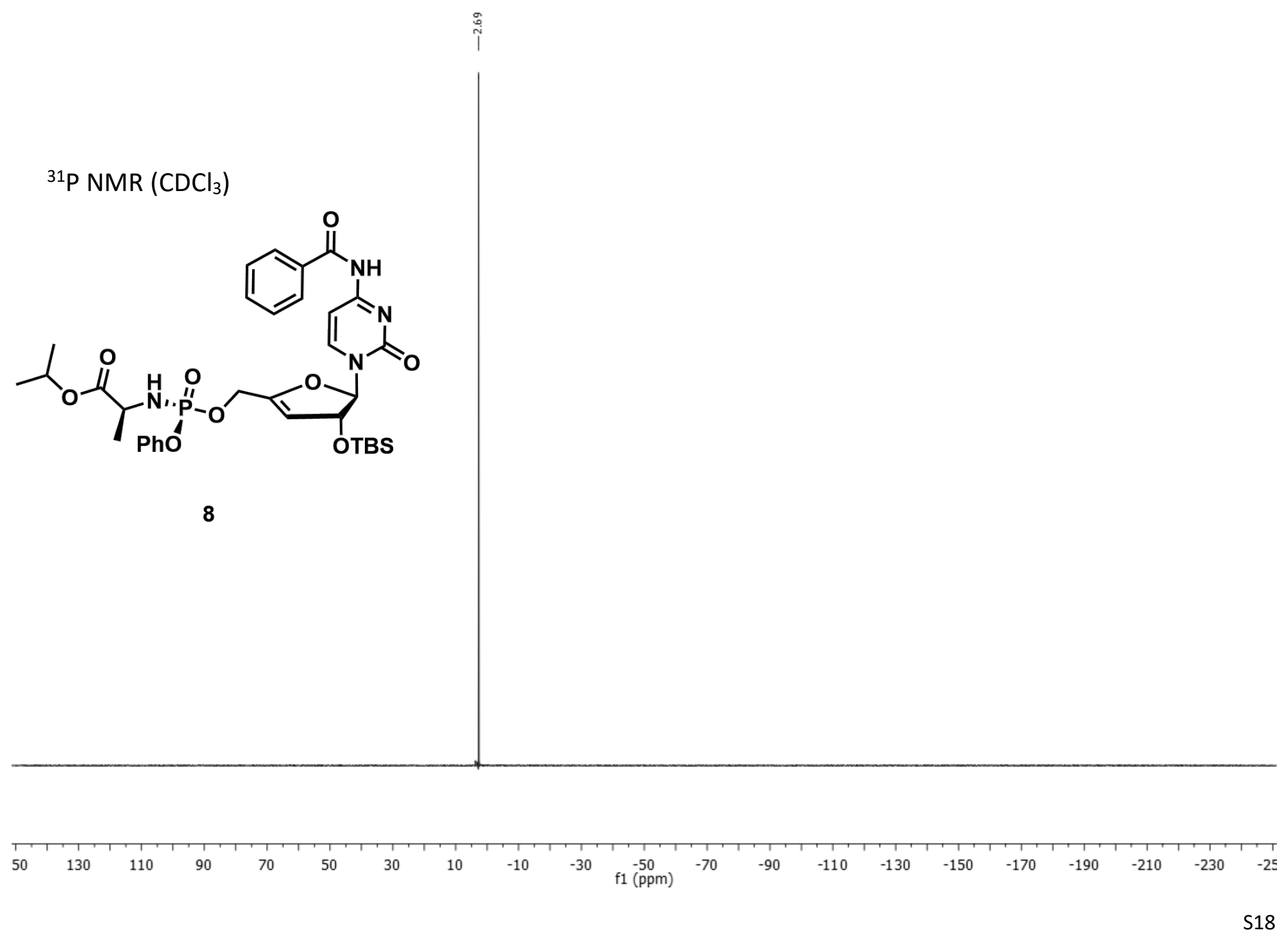


${ }^{1} \mathrm{H} \mathrm{NMR}\left(\mathrm{CDCl}_{3}\right)$

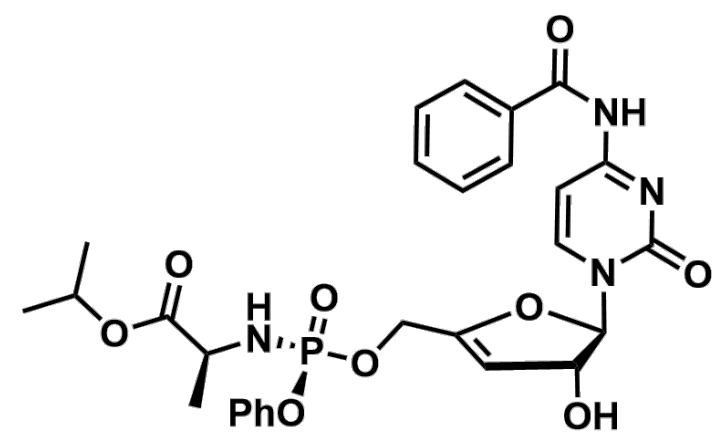

9

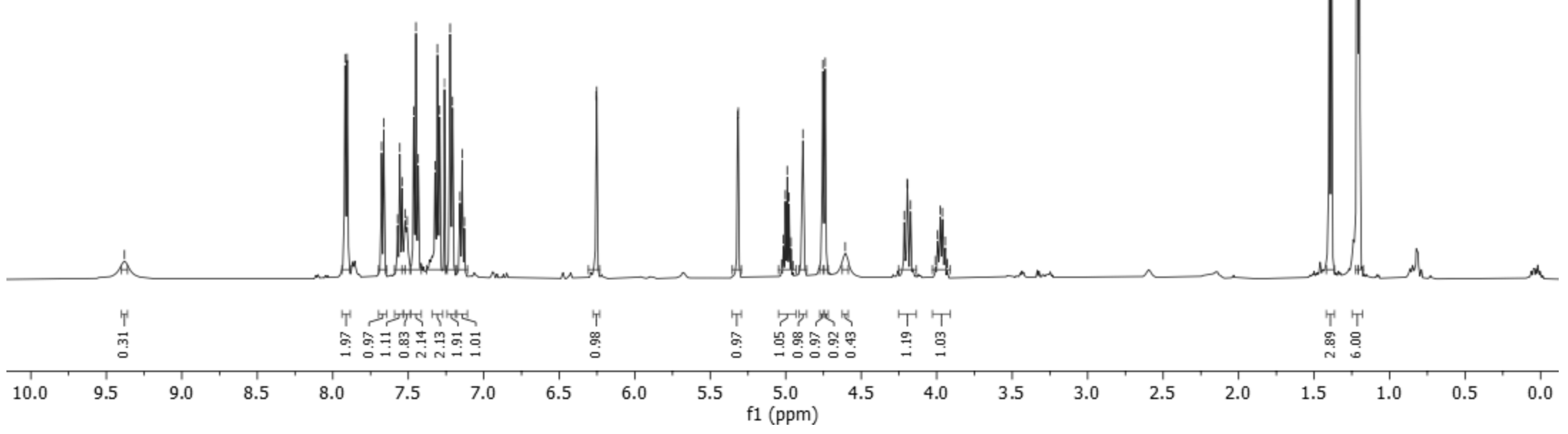




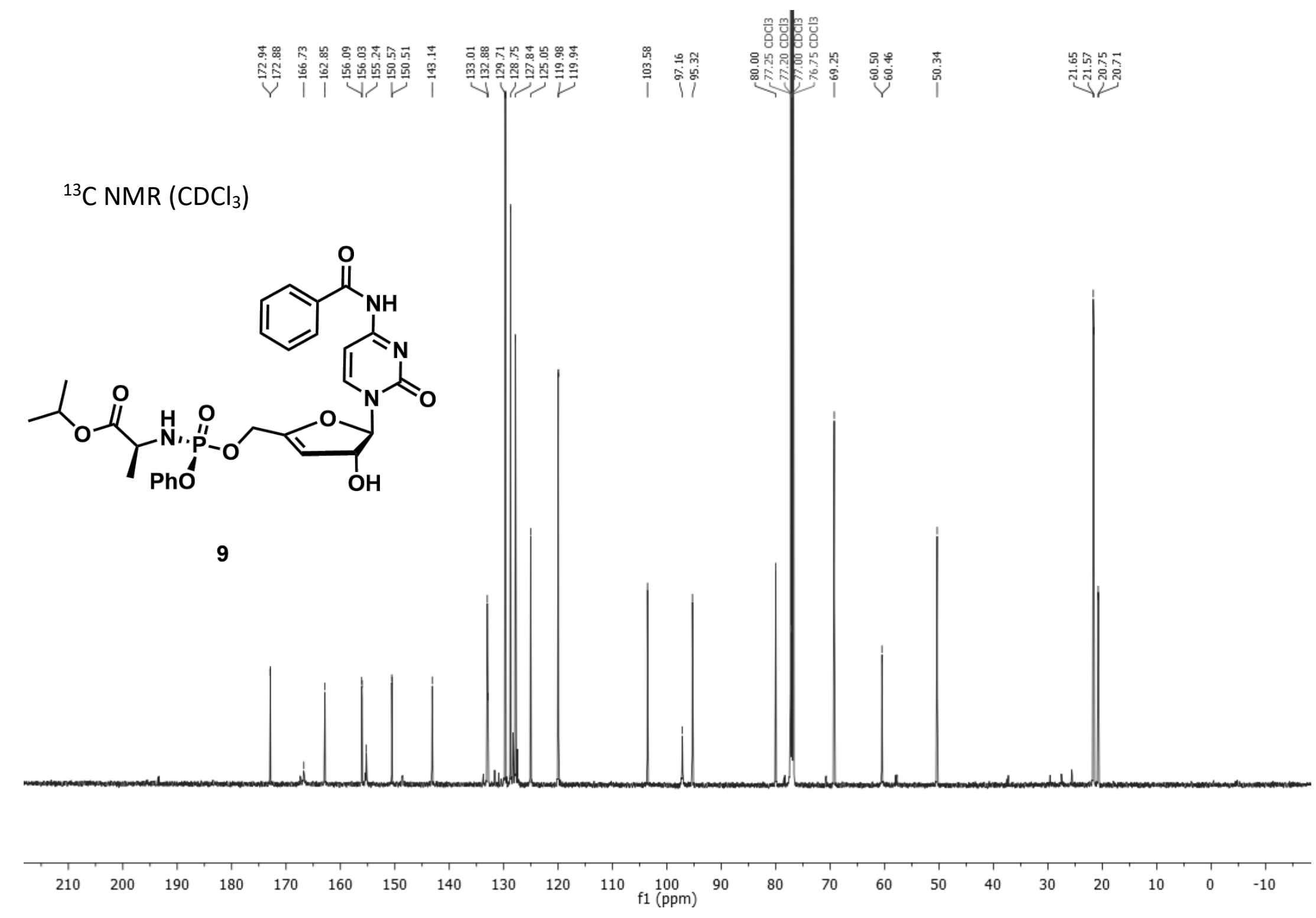




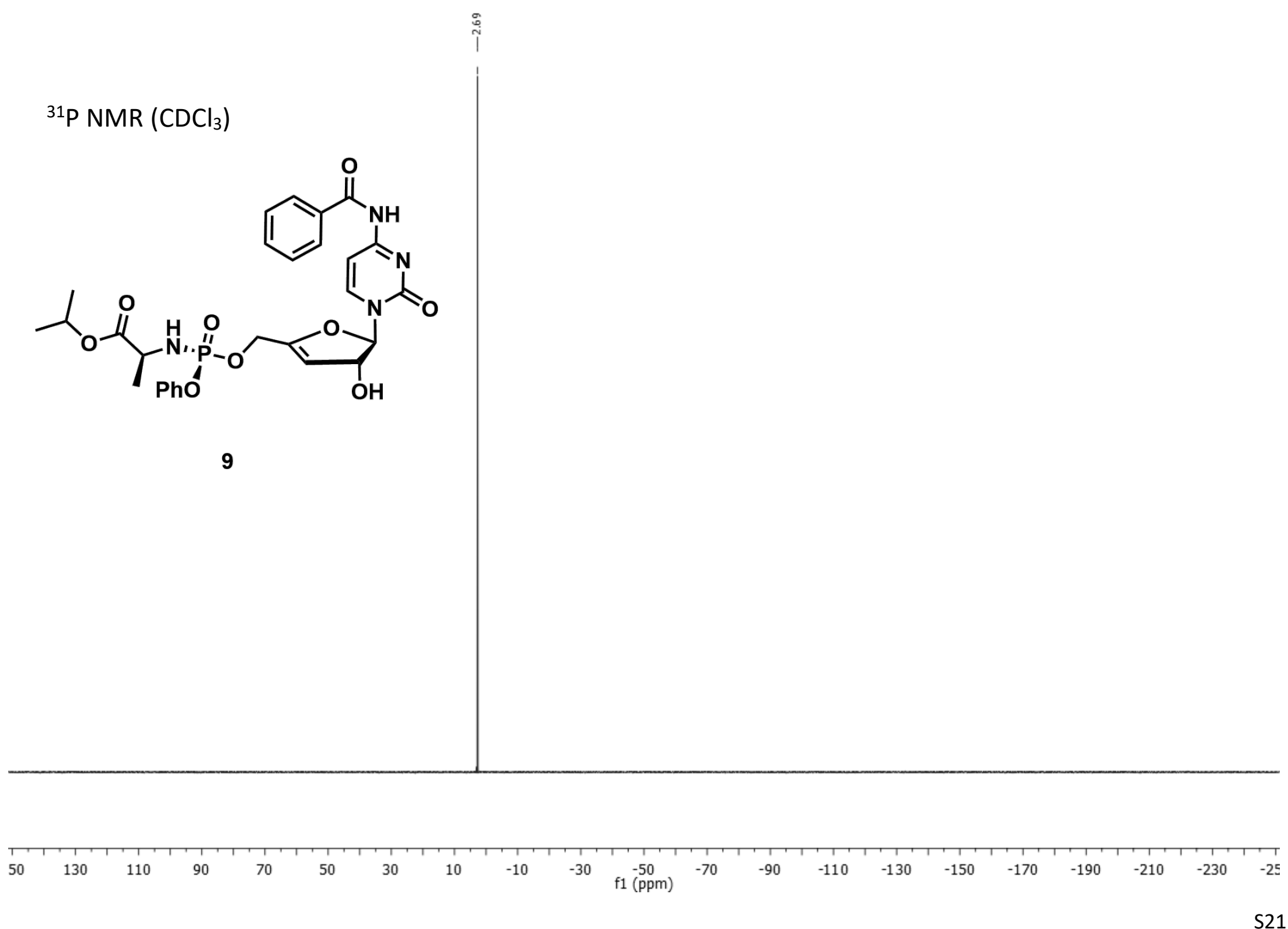




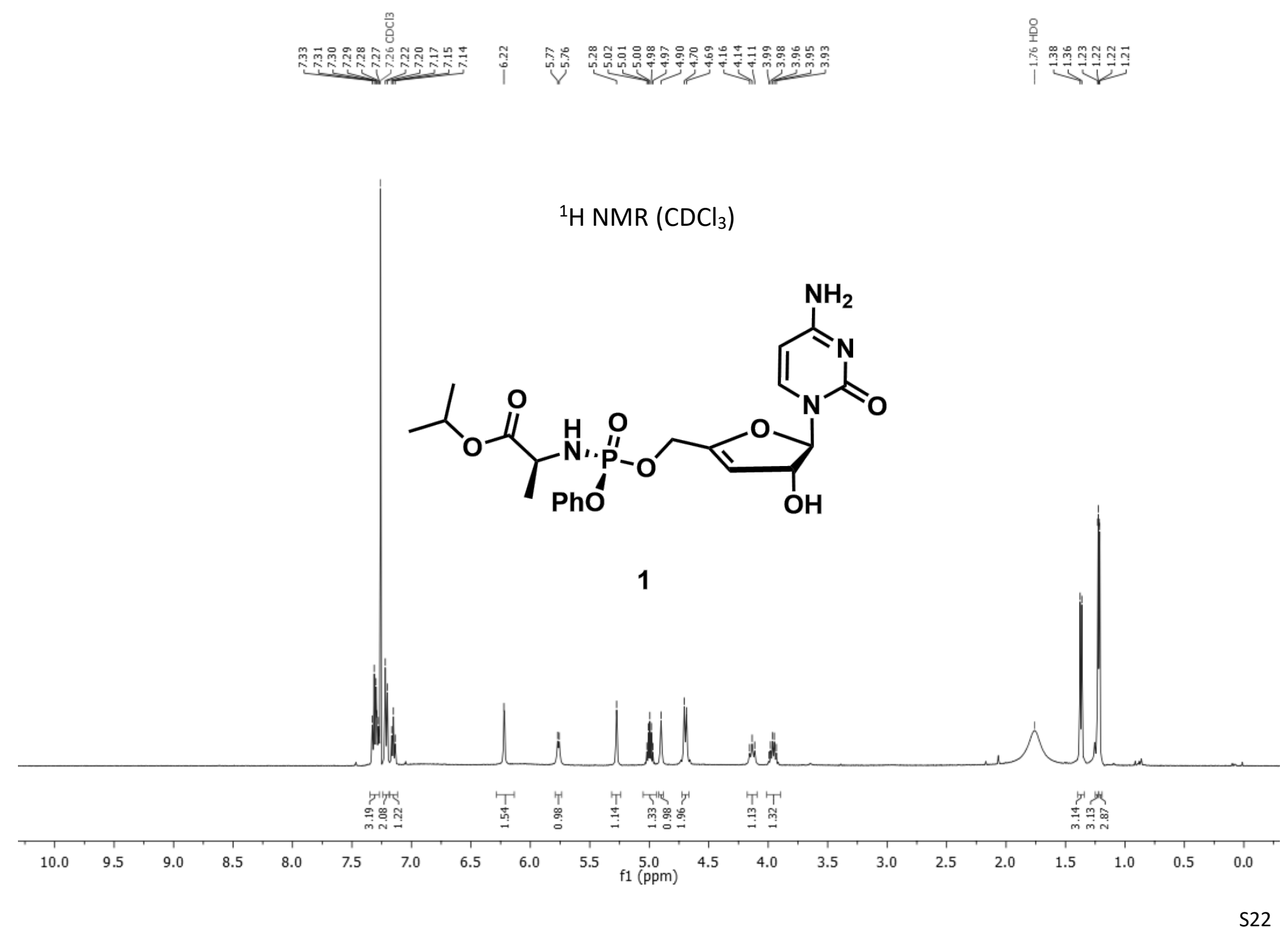




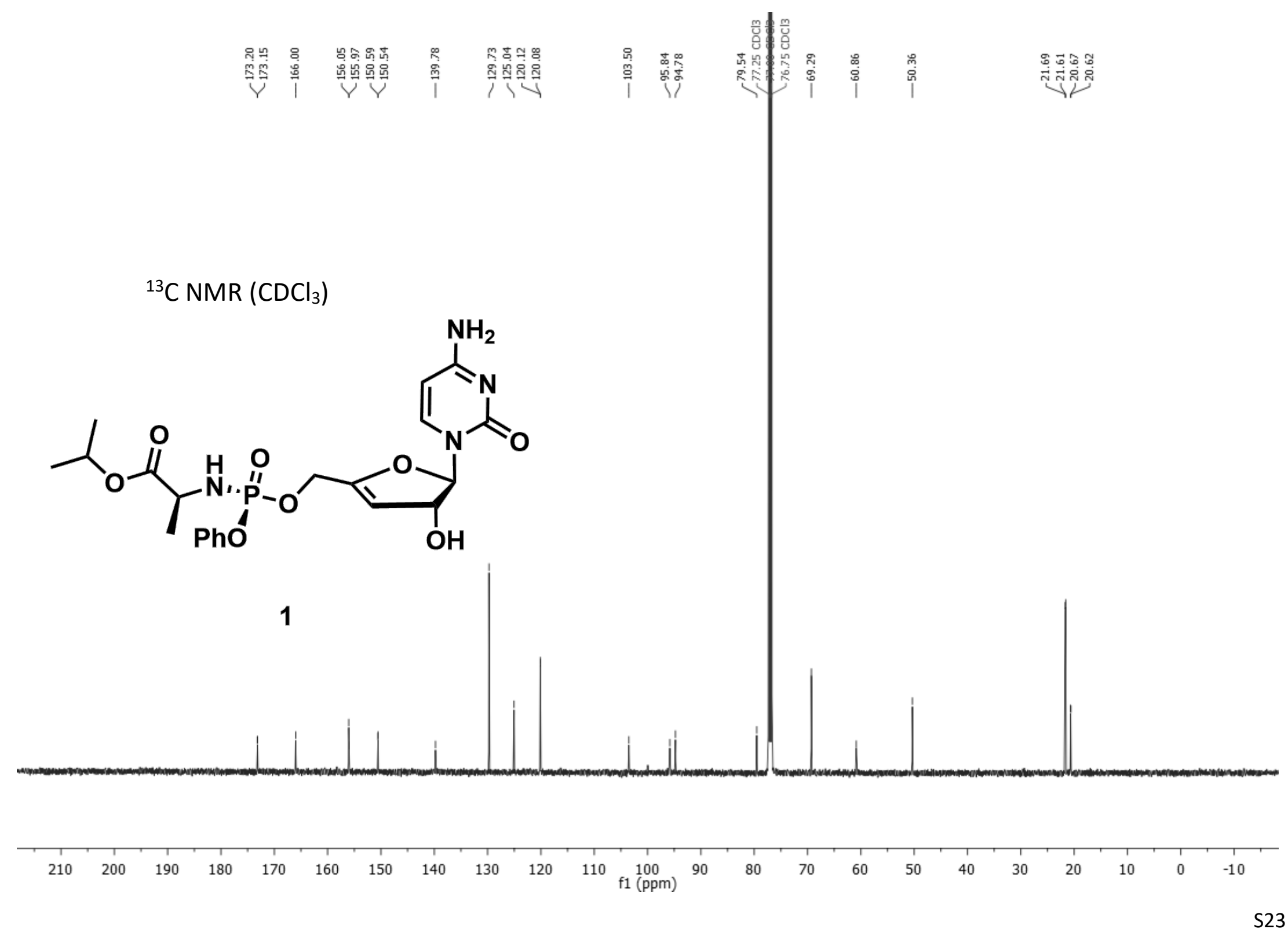




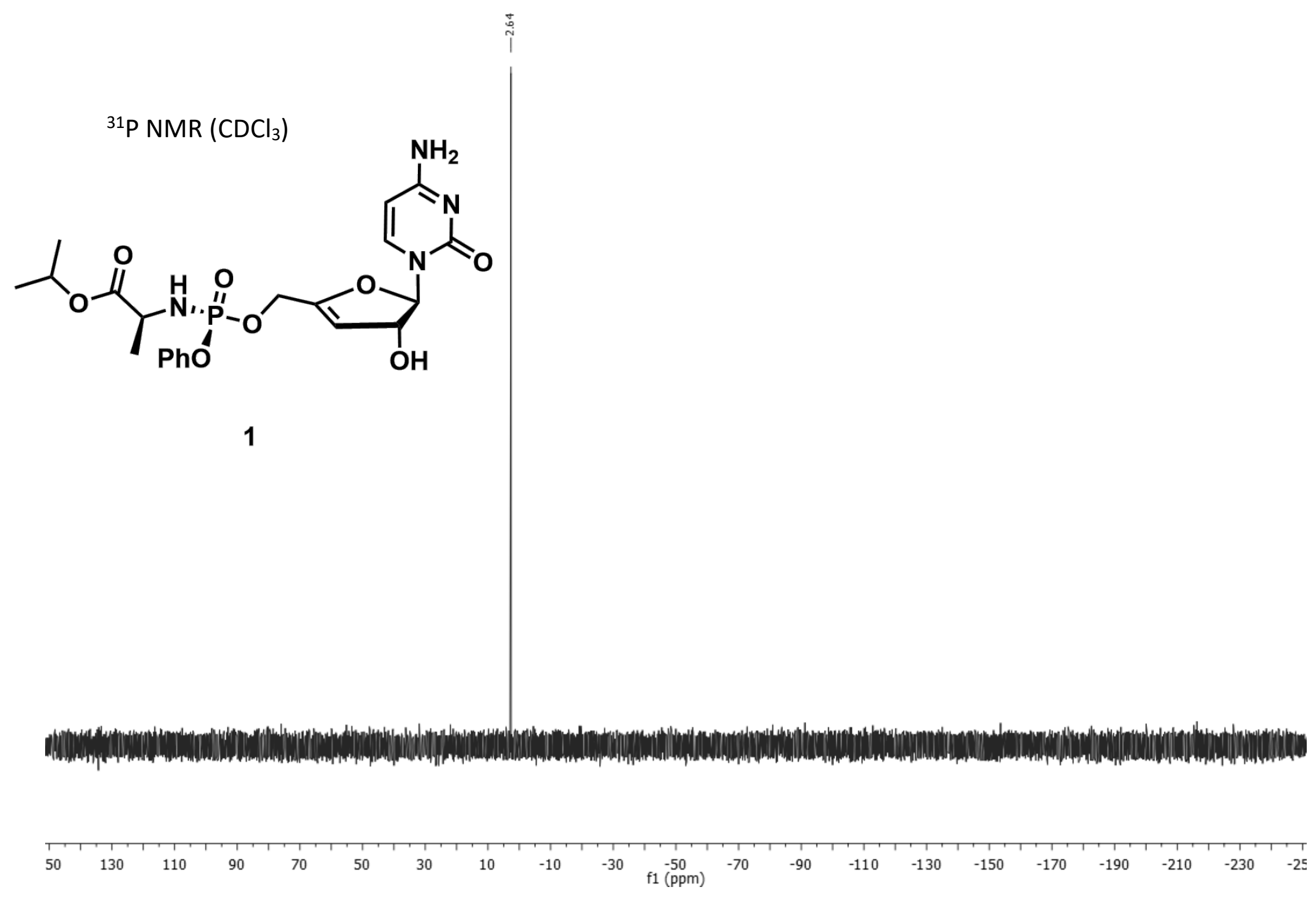



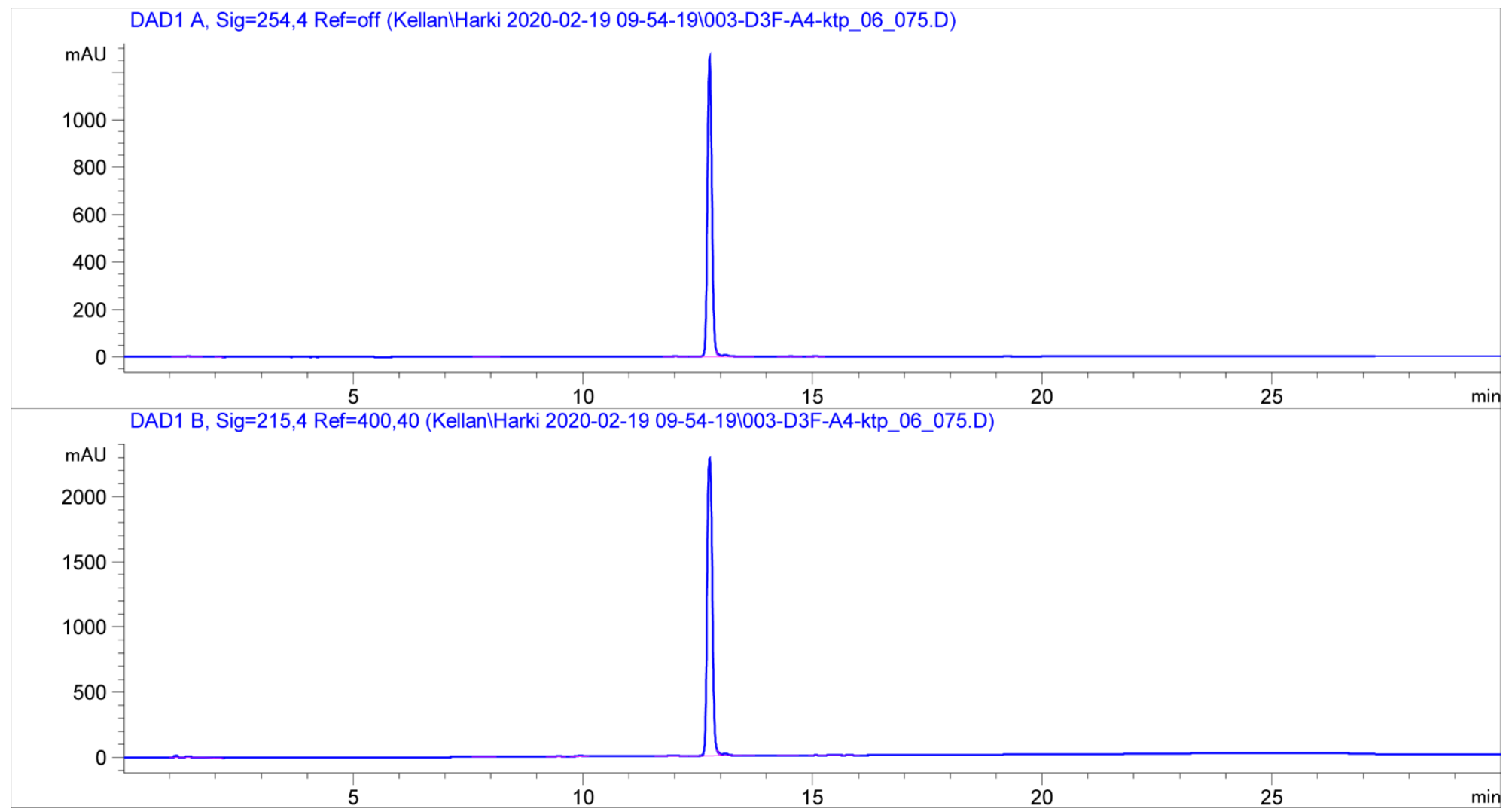

Representative analytical HPLC trace for purified 1 used in biological assays. Top: $254 \mathrm{~nm}$ UV signal, bottom: $215 \mathrm{~nm}$ signal. C18 column using $\mathrm{H}_{2} \mathrm{O}$ and $\mathrm{MeCN}$ with $0.1 \%$ TFA as eluents. Purity at $254 \mathrm{~nm}$ : $97 \%$; purity at $215 \mathrm{~nm}$ : $96 \%$. 


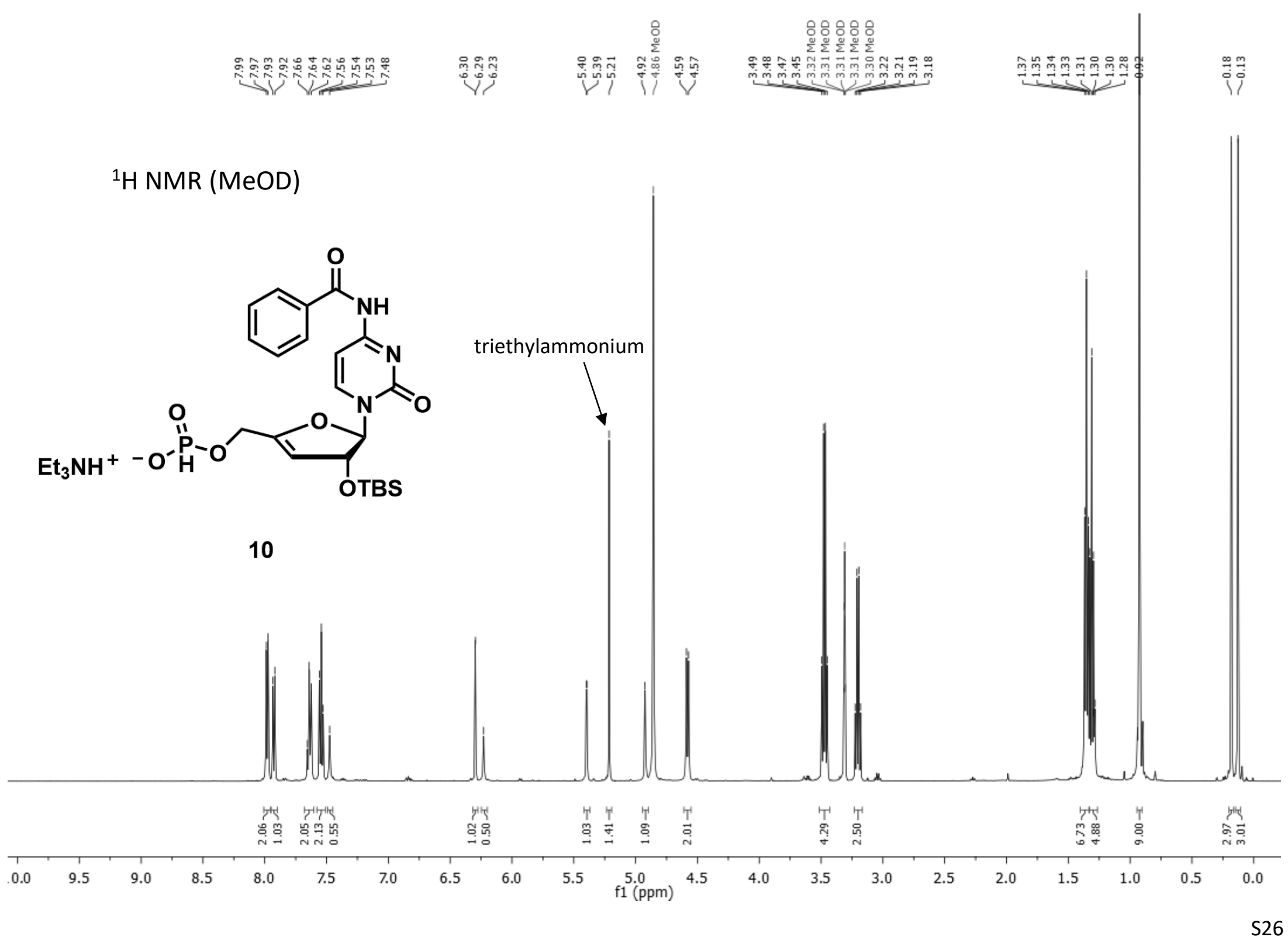




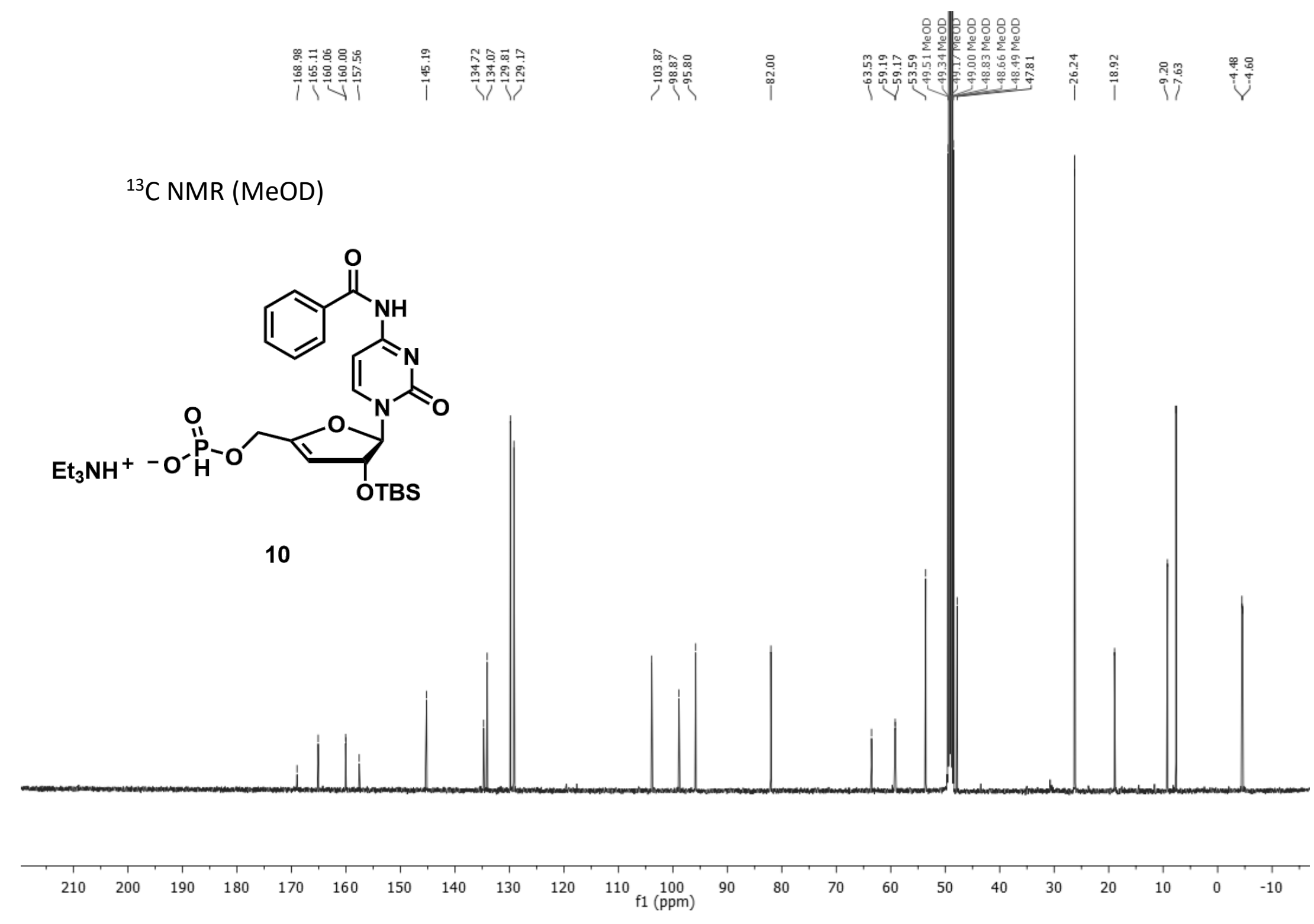




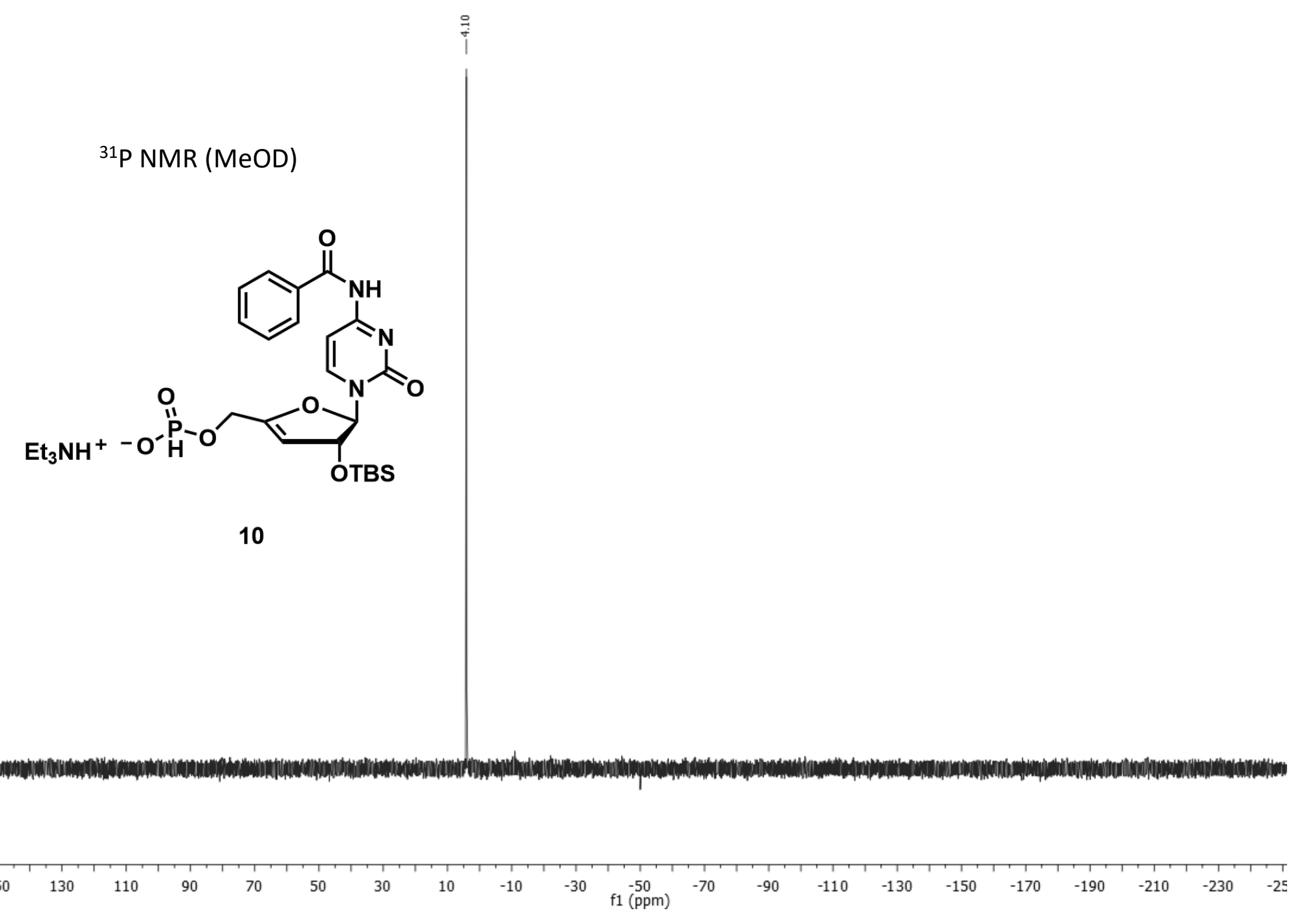




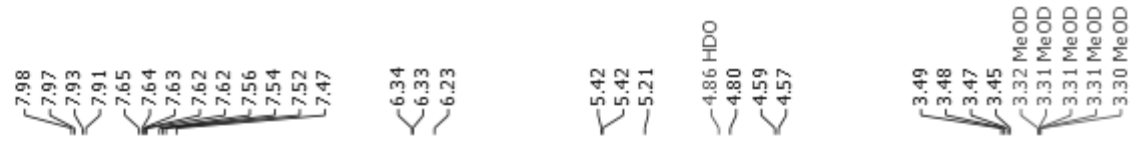

${ }^{1} \mathrm{H}$ NMR (MeOD)

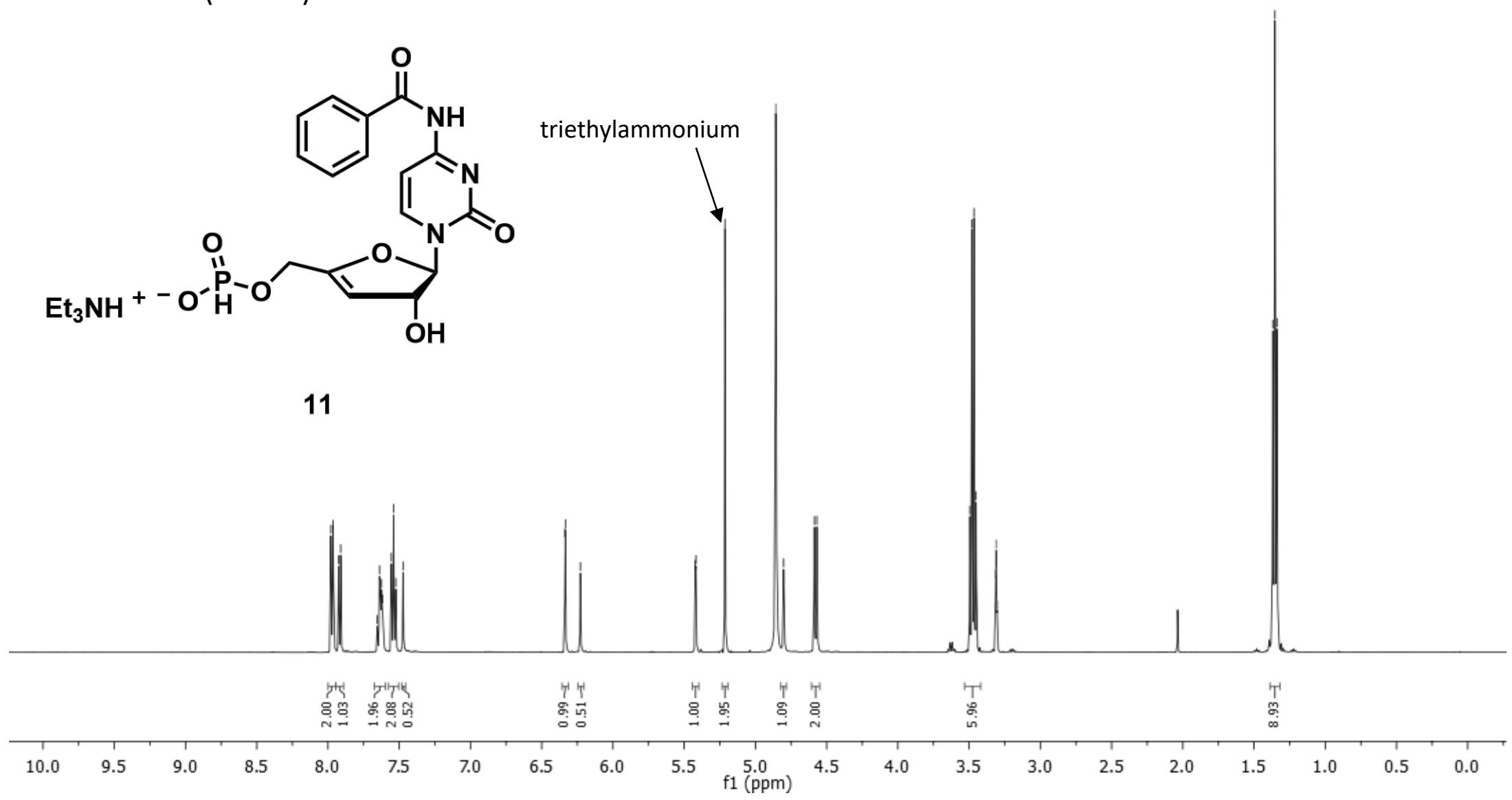




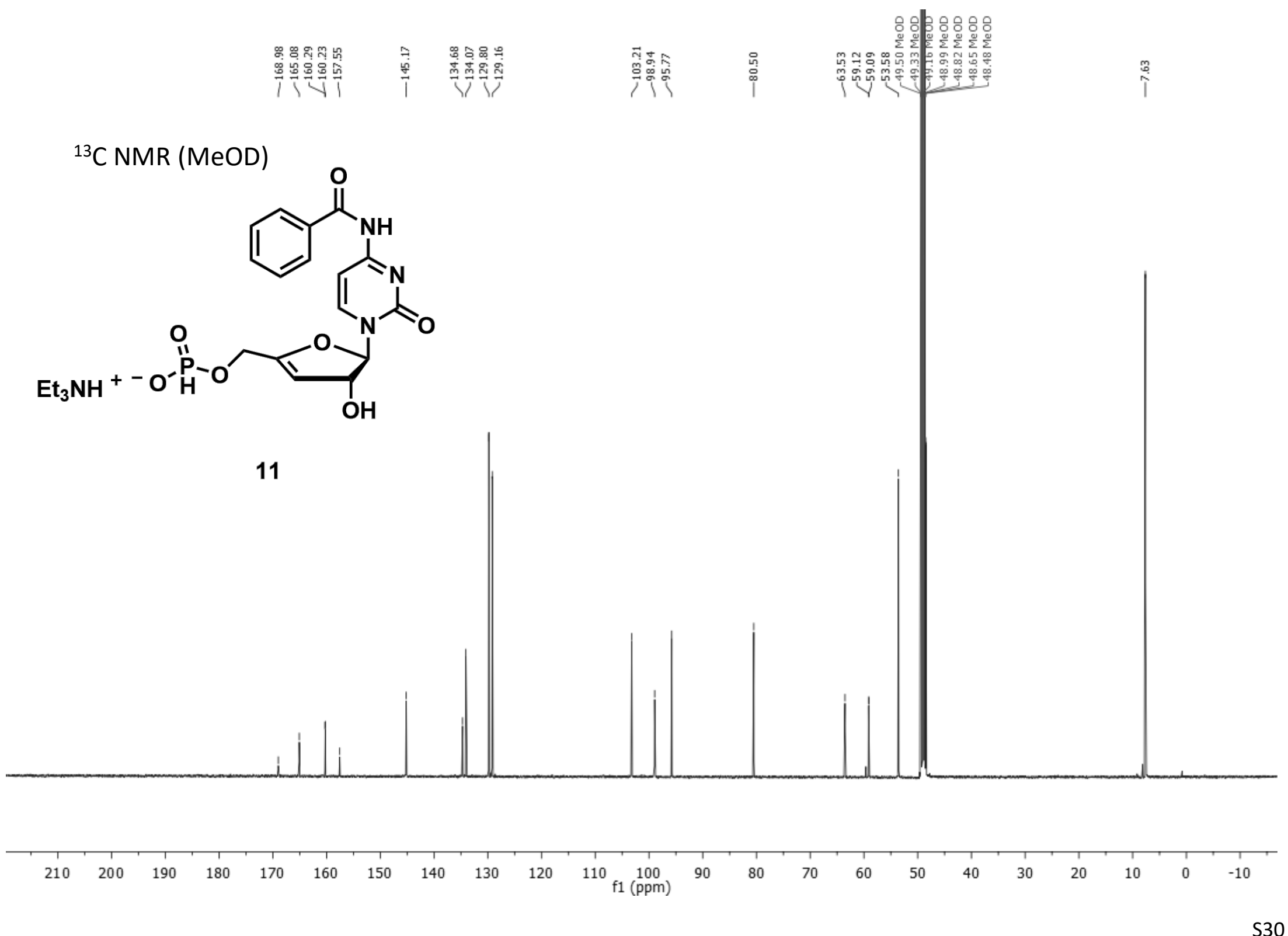



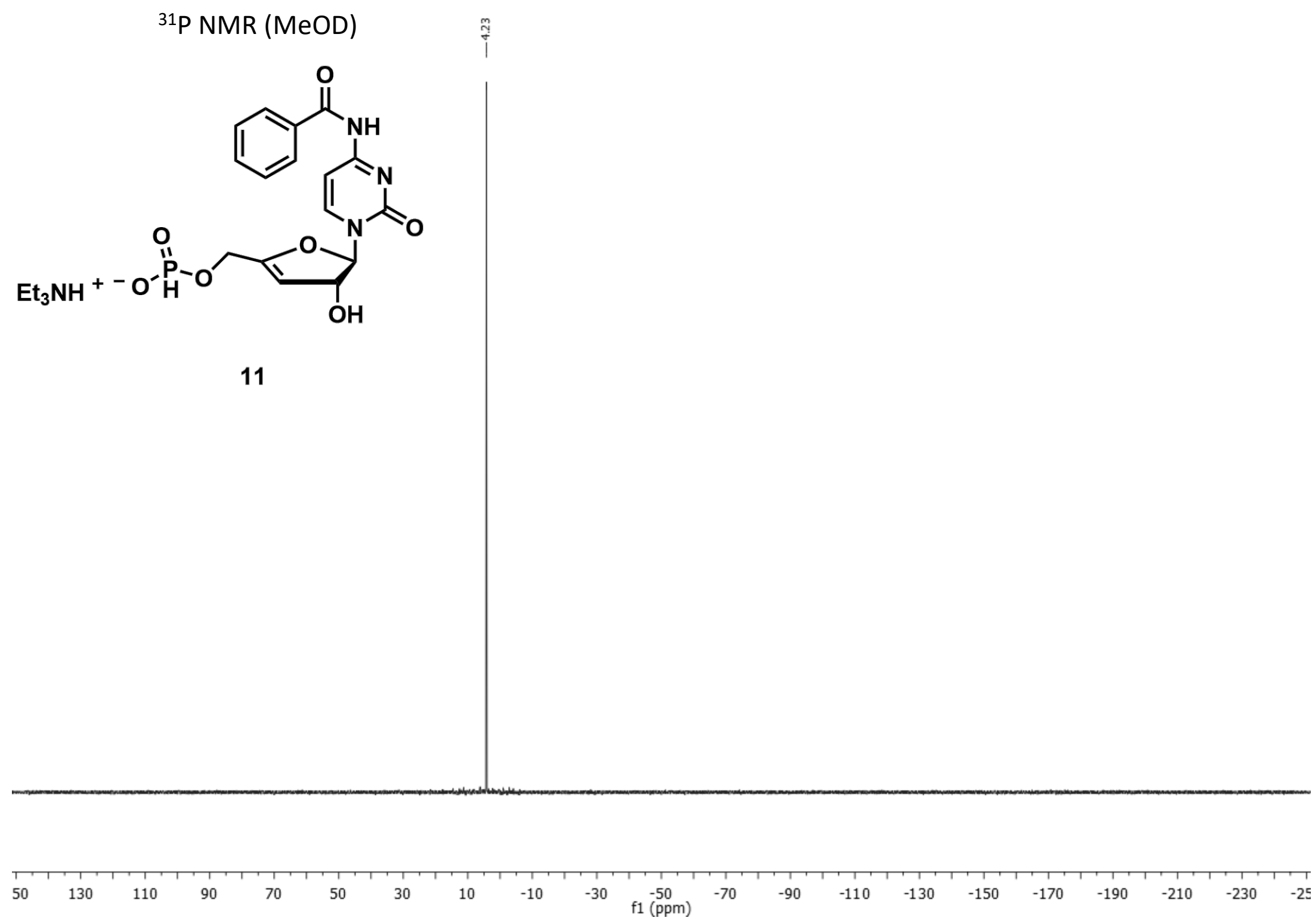
${ }^{1} \mathrm{H} \operatorname{NMR}\left(\mathrm{D}_{2} \mathrm{O}\right)$

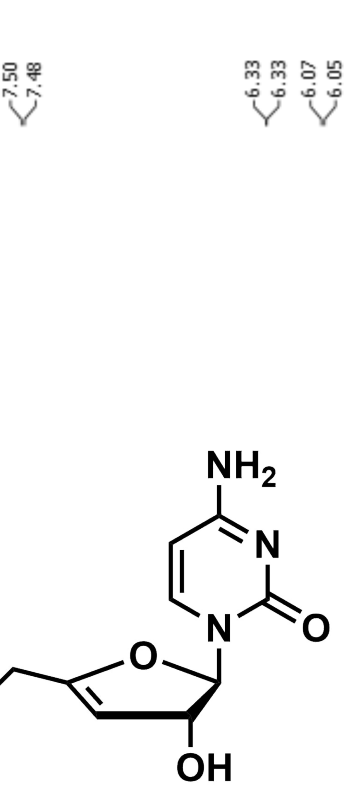

ddhCTP
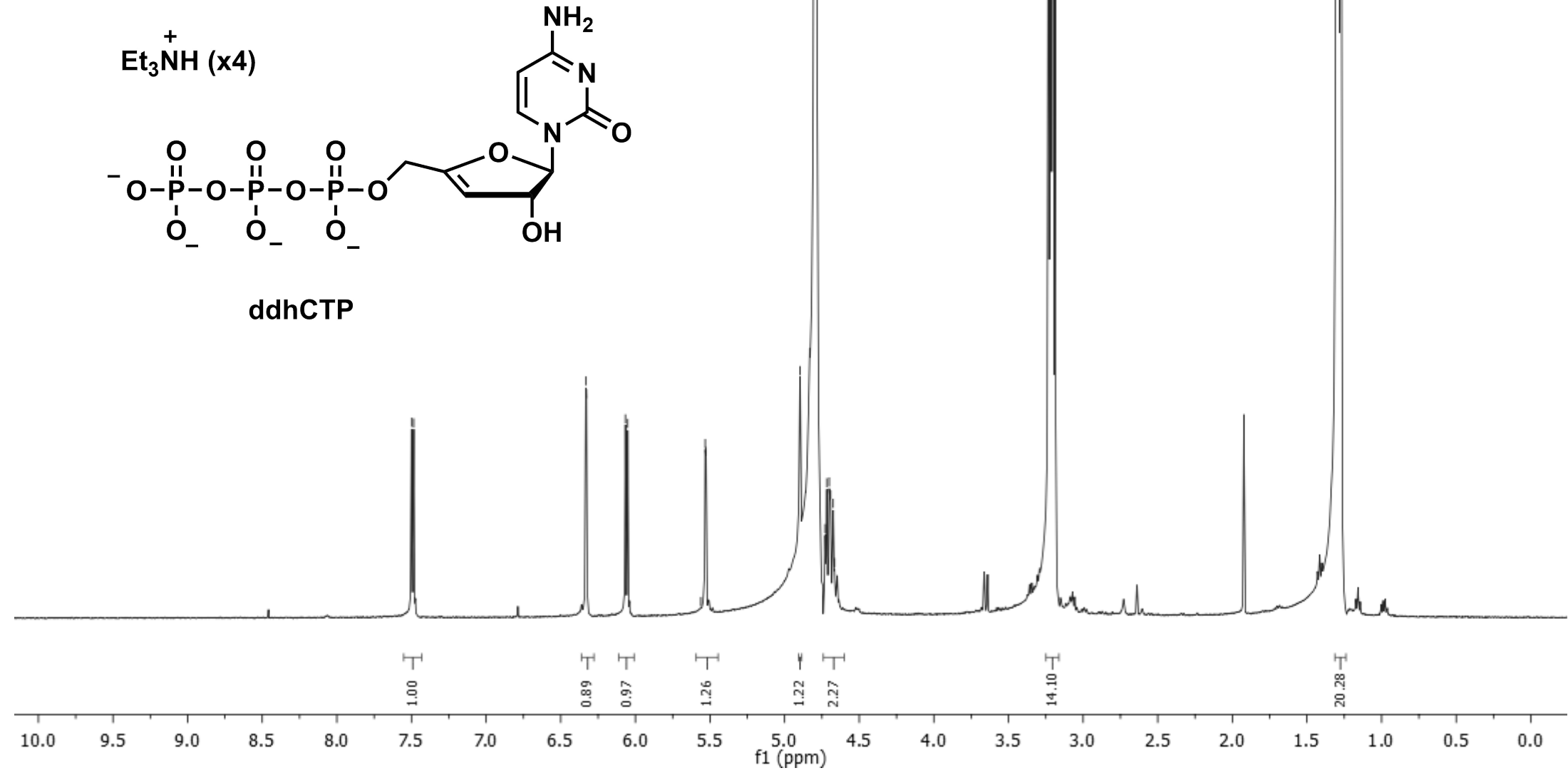


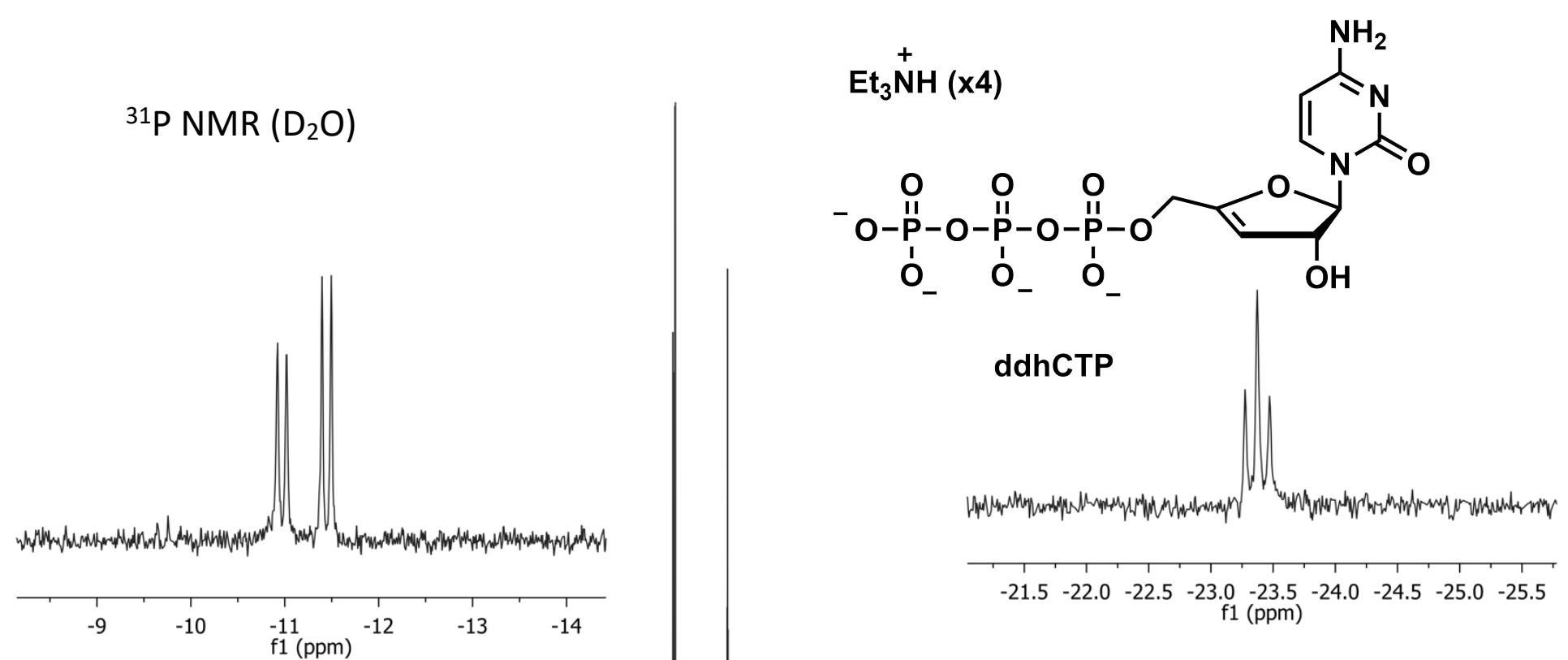

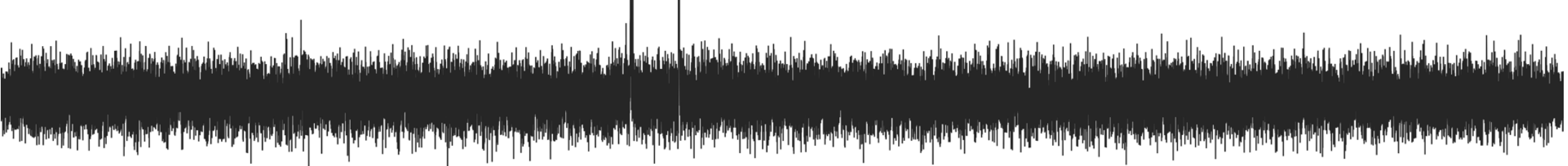

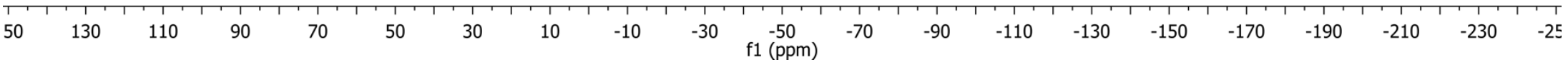


DAD1 A, Sig=270,4 Ref=off (KELLAN\Harki 2019-06-23 10-17-2610032019-06-2311-18-39.D)

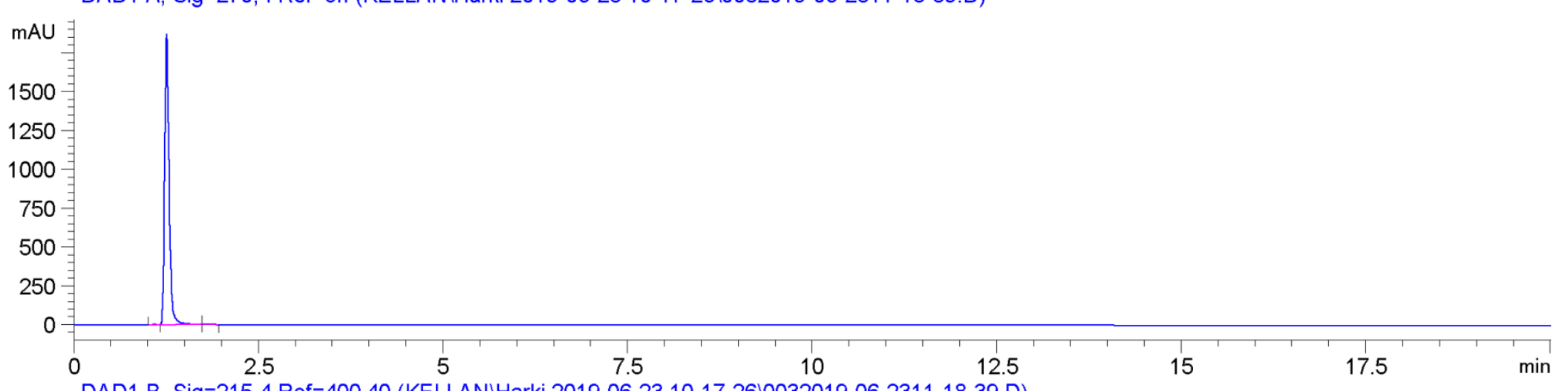

DAD1 B, Sig=215,4 Ref=400,40 (KELLAN\Harki 2019-06-23 10-17-2610032019-06-2311-18-39.D)

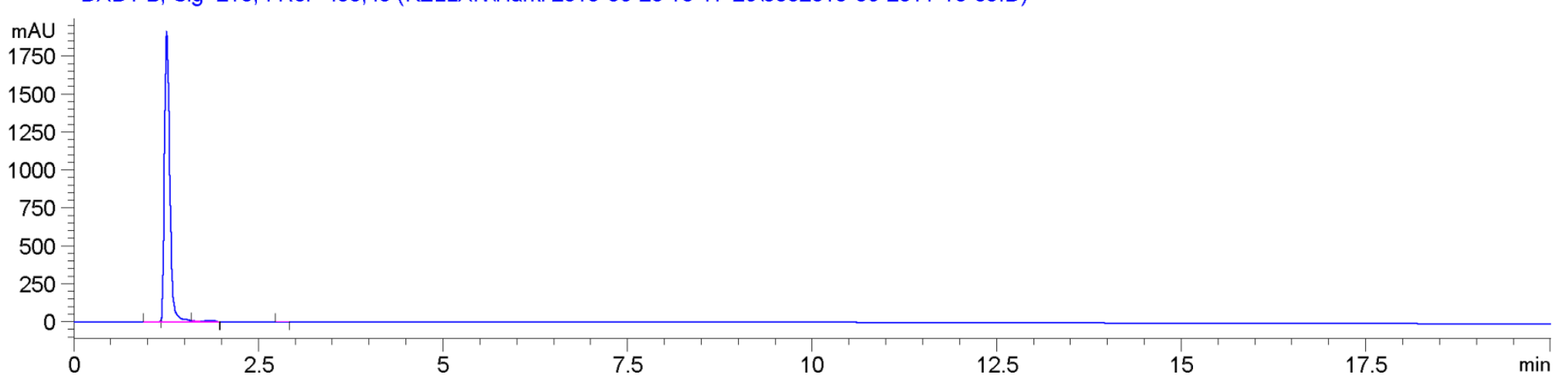

Analytical HPLC Trace of ddhCTP. Top: $270 \mathrm{~nm}$ UV signal, bottom: $215 \mathrm{~nm}$ signal. C18 Column using potassium phosphate buffer system. Purity at $270 \mathrm{~nm}$ : >99\%; purity at $215 \mathrm{~nm}$ : 94\%. 


\section{Reference}

1. Sofia, M. J.; Bao, D.; Chang, W.; Du, J. F.; Nagarathnam, D.; Rachakonda, S.; Reddy, P. G.; Ross, B. S.; Wang, P. Y.; Zhang, H. R.; Bansal, S.; Espiritu, C.; Keilman, M.; Lam, A. M.; Steuer, H. M. M.; Niu, C. R.; Otto, M. J.; Furman, P. A.; Discovery of a $\beta$-D-2'-Deoxy-2'-Alpha-Fluoro-2'- $\beta$-C-Methyluridine Nucleotide Prodrug (PSI-7977) for the Treatment of Hepatitis C Virus. J. Med. Chem. 2010, 53, 7202. 